Published in final edited form as:

Nat Neurosci. 2017 March ; 20(3): 449-458. doi:10.1038/nn.4487.

\title{
Hormonal gain control of a medial preoptic area social reward circuit
}

\author{
Jenna A. McHenry ${ }^{1}$, James M. Otis ${ }^{1}$, Mark A. Rossi ${ }^{1}$, J. Elliott Robinson ${ }^{2}$, Oksana Kosyk ${ }^{1}$, \\ Noah W. Miller ${ }^{1}$, Zoe A. McElligott ${ }^{1,3}$, Evgeny A. Budygin ${ }^{1,4,5}$, David R. Rubinow ${ }^{1}$, and \\ Garret D. Stuber ${ }^{1,2,3,6,7, \#}$ \\ ${ }^{1}$ Department of Psychiatry, University of North Carolina at Chapel Hill, Chapel Hill, NC \\ ${ }^{2}$ Neuroscience Curriculum, University of North Carolina at Chapel Hill, Chapel Hill, NC \\ ${ }^{3}$ Bowles Center for Alcohol Studies, University of North Carolina at Chapel Hill, Chapel Hill, NC \\ ${ }^{4}$ Department of Neurobiology and Anatomy, Wake Forest School of Medicine, Winston-Salem, NC \\ ${ }^{5}$ Institute of Translational Biomedicine St. Petersburg State University, St. Petersburg, Russia \\ ${ }^{6}$ Department of Cell Biology and Physiology, University of North Carolina at Chapel Hill, Chapel \\ Hill, NC
}

${ }^{7}$ Neuroscience Center, University of North Carolina at Chapel Hill, Chapel Hill, NC

\section{Abstract}

\begin{abstract}
Neural networks that control reproduction must integrate social and hormonal signals, tune motivation, and invigorate social interactions. However, the neurocircuit mechanisms for these processes remain unresolved. The medial preoptic area (mPOA), an essential node for social behaviors and is comprised of molecularly-diverse neurons with widespread projections. Here, we identify a steroid-responsive subset of neurotensin (Nts) expressing mPOA neurons that interface with the ventral tegmental area (VTA) to form a socially-engaged reward circuit. Using in vivo 2photon imaging in female mice, we show that $\mathrm{mPOA}^{\text {Nts }}$ neurons preferentially encode attractive male cues compared to non-social appetitive stimuli. Ovarian hormone signals regulate both the physiological and cue encoding properties of these cells. Furthermore, optogenetic stimulation of

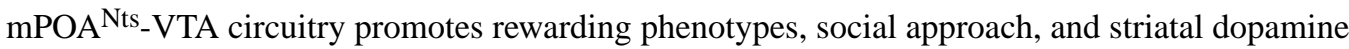
release. Collectively, these data demonstrate that steroid-sensitive mPOA neurons encode ethologically-relevant stimuli and co-opt midbrain reward circuits to promote prosocial behavior critical for species survival.
\end{abstract}

\footnotetext{
Users may view, print, copy, and download text and data-mine the content in such documents, for the purposes of academic research, subject always to the full Conditions of use:http://www.nature.com/authors/editorial_policies/license.html\#terms

\#Address correspondence to: Garret D. Stuber, Ph.D., Associate Professor, Departments of Psychiatry \& Cell Biology and Physiology, Neuroscience Center, University of North Carolina at Chapel Hill, Tel: +1 (919) 843-7140, Fax: +1 (919) 966-1050, gstuber@med.unc.edu.

Author Contributions

JAM and GDS designed the experiments and wrote the manuscript with input from all authors. JMO and JER performed physiology recordings. EAB performed FSCV recordings. MAR wrote codes for in vivo imaging data analysis. OK and ZAM performed in situ hybridization. NWM assisted with tissue processing. JAM performed all surgeries, behavioral assays, 2-photon and confocal imaging experiments. DRR and GDS supervised the project.

The authors declare no competing financial interests.
} 
Prosocial behaviors, such as mating and parenting, are innately rewarding across mammals and require complex neural computations to decipher social signals and promote actions that facilitate offspring and species survival ${ }^{1-3}$. Social communication strategies are often species-specific and social cues (e.g., from a potential mate or the infant) are transmitted through multiple sensory modalities to facilitate social interactions ${ }^{3,4}$. Further, internal circulating gonadal steroids, including estradiol in females, change as a function of reproductive status and alter the processing of social cues to bias animals towards social incentives and facilitate reproductive behaviors ${ }^{4-7}$. However, the neural mechanisms by which social and hormonal signals recruit neurocircuits to adjust motivational states for reproductive behaviors over competing needs remain poorly understood.

The medial preoptic area (mPOA) is a functionally and chemically conserved node of the social behavior network ${ }^{8}$ that is essential for reproductive behavior in all vertebrate species studied $^{3,4,9}$. Further, the mPOA contains many steroid receptor containing neurons, receives social information from multiple sensory modalities, and has widespread projections throughout the brain, including the ventral tegmental area (VTA) $)^{3,4,6,7}$. While mPOA-VTA projections are necessary for the expression of reproductive behaviors, it is unknown whether mPOA circuits that encode social and hormonal signals convey positive valence and orchestrate the appetitive and reinforcing aspects of these behaviors. Since VTA dopamine neurons provide incentive salience signals to direct motivation for a variety of needs essential for survival ${ }^{10,11}$, we predict that neurons in these two brain regions interface to form a socially-engaged reward circuit.

Here, we targeted a molecularly-defined VTA-projecting population of mPOA neurons that express the gene neurotensin (Nts) and examined their endogenous cue-encoding dynamics and behavioral circuit properties under social and hormonal contexts. Previous studies have been unable to chronically record in vivo neural activity from molecularly-defined mPOA neurons. To circumvent these challenges, we implemented in vivo deep-brain calcium $\left(\mathrm{Ca}^{2+}\right)$ imaging using 2-photon microscopy in head-fixed, awake female mice and reliably detect $\mathrm{Ca}^{2+}$ signals from the same neurons over many days with single-neuron, cell-type precision. Using this approach, we compare the activity dynamics of individual $\mathrm{mPOA}^{\mathrm{Nts}}$ neurons in response to different types of attractive odor cues and track social odor responses across hormonal states. We also perform ex vivo slice electrophysiology and $\mathrm{Ca}^{2+}$ imaging to identify physiological relationships between reproductive steroids and $\mathrm{mPOA}^{\mathrm{Nts}}$ cell excitability. Lastly, we utilize in vivo behavioral optogenetics to characterize mPOA-VTA ${ }^{\mathrm{Nts}}$ circuitry under social, hormonal, and reward-seeking contexts and in conjunction with fastscan cyclic voltammetry (FSCV) to detect mPOA-VTA $^{\text {Nts- }}$ evoked dopamine release in the ventral striatum.

\section{Results}

\section{Identification of a molecularly-defined population of steroid-responsive mPOA-VTA neurons}

Since diverse cell types have been reported in VTA-projecting mPOA neurons ${ }^{12,13}$ and molecular subsets of mPOA populations putatively regulate different types or aspects of 
social behaviors ${ }^{14}$, we first sought to identify a molecularly-defined population of steroidresponsive mPOA-VTA projecting neurons. The gene encoding for the peptide Nts is prominently expressed in the $\mathrm{mPOA}^{4}$ and in other hypothalamic regions has been shown to promote reward-seeking through VTA projections ${ }^{15}$. Here, injections of retrogradely transported beads into the VTA of female mice resulted in substantial labeling of mPOA neurons, with $96 \%$ of $N t$-labeled cells co-expressed with VTA beads (Fig.1a,b). This subpopulation comprised 35\% of al mPOA-VTA projecting neurons (Fig.1a,b). Further, 21\% of Nts mPOA neurons co-expressed mRNA for the estrogen receptor a/1 (ESRI) and galanin (Gal) (Fig.1c-g), which the latter cell population was recently shown to govern parental behaviors in mice ${ }^{14}$. Another $63 \%$ contained mRNA for ESR 1 but not $G a l$, and only 3\% expressed Gal but not ESR1 (Fig.1c-g). While the majority of Nts cells expressed ESR1 (84\%) (Fig.1c-g and S1c,d), this appeared to be a subpopulation of all mPOA ESR 1 cells.

Previous studies in female rodents indicate that Nts mPOA expression peaks in proestrus and is enhanced by estradiol ${ }^{16-18}$. We extended these findings to show that $95 \%$ of $N t s$ mPOA cells co-expressed the gene for vesicular GABA transporter ( $\mathrm{Vgat}$ ), and 18\% of these also had low to moderate levels of vesicular glutamate transporter (Vglut2), and only 5\% expressed Vglut2 alone (Fig.S2a-h). These proportions did not vary as a function of the hormonal state, however administration of estradiol in ovariectomized females increased both mPOA Nts and Vgat mRNA expression intensity compared with vehicle-treated controls (Fig. S2d-h). Collectively, these data indicate that Nts-containing mPOA neurons comprise a subpopulation of putative GABAergic neurons that project to the VTA, largely express ESR1 steroid receptors, and are responsive to gonadal steroid changes.

\section{mPOA-VTA ${ }^{\text {Nts }}$ neurons dynamically encode social odor cues}

Next, we monitored the endogenous activity dynamics of $\mathrm{mPOA}^{\mathrm{Nts}}$ neurons in response to innately attractive social odor cues using in vivo 2-photon $\mathrm{Ca}^{2+}$ imaging with single-neuron and cell-type precision, in awake female mice. Here, a Cre-inducible virus coding for the fluorescent $\mathrm{Ca}^{2+}$ indicator, GCaMP6s ${ }^{19}$, was injected into the mPOA (mPOA ${ }^{\mathrm{Nts}:: G C a M P 6 s}$ ) of Nts-IRES-Cre mice ${ }^{20}$, which co-expressed Cre in Nts-containing mPOA neurons (Fig. $\mathrm{S} 3 \mathrm{a}-\mathrm{e})$. Dual $\mathrm{Ca}^{2+}$ imaging and whole-cell patch clamp recordings first established that increasing current injections produced increasing amounts of $\mathrm{Ca}^{2+}$ mediated fluorescence

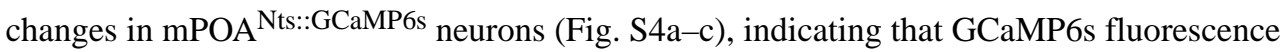
correlated with evoked action potentials and can thus serve as a proxy for neural activity. To visualize $\mathrm{Ca}^{2+}$ activity in vivo, we gained optical access to this deep brain region through a Gradient Refractive Index (GRIN) lens implanted directly above mPOA Nts::GCaMP6s neurons and applied a head-ring for subsequent 2-photon imaging (Fig.S4d-f and Fig.2a). Following recovery and time to permit for GCaMP6 expression, mPOA ${ }^{\text {Nts::GCaMP6s }}$ neurons from female mice in proestrus were imaged during multiple time-locked, automated trials where vaporized social odors were presented (Fig.2a). Intact male urine served as an attractive social cue with reproductive relevance and ovariectomized female urine served as a conspecific urine control; both odor types were innately attractive to female mice (Fig.S5ag). $\mathrm{Ca}^{2+}$ dynamics were reliably detected in individual mPOA ${ }^{\mathrm{Nts}: \text { GCaMP6s }}$ cells with singleneuron precision (Fig.2b,c, Fig.S4d-f, and Video 1) and we identified a subset of individual $\mathrm{mPOA}^{\mathrm{Nts}}$ neurons that were preferentially excited by male odor (Fig.2b-d and Video 2 ). 
Across all animals tested, a greater proportion of $\mathrm{mPOA}^{\mathrm{Nts}:: G C a M P 6 s}$ cells were excited by male odor (37\%) compared with female odor (8\%) (Fig.2d). Moreover, a direct odor-type comparison of cells that were significantly excited by male odor revealed that male-excited cells were relatively less responsive to female odor (Fig.2e). These data illustrate that a large portion of $\mathrm{mPOA}^{\mathrm{Nts}}$ neurons dynamically encode social odor cues, with subsets preferentially responding to reproductively-relevant male signals.

\section{$\mathrm{mPOA}^{\mathrm{Nts}}$ neurons encode reproductive male cues in a steroid-gated manner}

Gonadal steroids, including estradiol, can enhance the processing of reproductive social signals, promote mate attraction ${ }^{5,21}$, and differentially regulate mPOA neuronal activity in vivo $^{22,23}$ (which could reflect differences in cell types or steroid receptor expression). We next evaluated whether ovarian steroids influence social cue-encoding dynamics, by tracking odor-evoked $\mathrm{Ca}^{2+}$ activity from the same $\mathrm{mPOA}^{\mathrm{Nts}:: G C a M P 6 s}$ neurons before and after steroid-priming in ovariectomized females, over days (Fig.3a). In a separate cohort of ovariectomized females, steroid priming of estradiol approximately 5 hours before testing enhanced behavioral attraction to male urine and this behavioral response was sustained following a second injection of progesterone (a steroid regimen known to induce sexual receptivity), compared with vehicle treatment (Fig.S6a-e and Fig. 3a,b). Using this priming schedule for imaging, we detected $\mathrm{Ca}^{2+}$ dynamics from the same neurons across repeated imaging sessions separated by days and identified individual cells that encoded male odor only after steroid replacement (Fig.3a). The amplitude and proportion of cells excited by male odor increased following estradiol replacement and was sustained following progesterone administration, compared with vehicle treatment (Fig.3e-f and S6f,g). In contrast, female odor presentation excited a smaller proportion of cells following either treatment (Fig.3f and S6h). Together, this indicates that $\mathrm{mPOA}^{\mathrm{Nts}}$ neurons adjust their male odor encoding properties in response to changes in ovarian steroids and that these cells integrate changes in external and internal context that shift activity patterns.

\section{$\mathrm{mPOA}^{\mathrm{Nts}}$ encoding comparison of social and nonsocial attractive odor cues}

While $\mathrm{mPOA}^{\mathrm{Nts}}$ neurons encoded attractive social cues, it remained unclear whether this was restricted to social signals or generalized to nonsocial forms of appetitive odors. Peanut oil is a robustly attractive, nonsocial, food-related odor $^{24}$ and we confirmed that female mice are behaviorally attracted to this stimulus following prior exposure in the home cage (Fig.S5a-g). Then, we imaged odor-evoked $\mathrm{mPOA}^{\mathrm{Nts}:: G C a M P 6 s} \mathrm{Ca}^{2+}$ responses in primed females during multiple distinct odor trials of social and nonsocial attractive odors. Specifically, we compared neuronal responses to urine odor from intact males, urine odor from intact females, and peanut oil odor (after home cage exposure) (Fig.4a,b). Individual neurons were excited by male urine and/or female urine, but these cells were largely unresponsive to or inhibited by peanut oil odor presentation (Fig.4a-c). Further, a greater proportion of neurons were excited by male urine odor (28\%) compared to intact female urine odor ( $8 \%$ ) or peanut oil odor (10\%) (Fig.4d). These single-neuron comparisons demonstrate that distinct forms of attractive stimuli can recruit largely non-overlapping $\mathrm{mPOA}^{\mathrm{Nts}}$ neuron ensembles, and that social versus nonsocial appetitive cue encoding is dissociable at the individual neuron level. 


\section{Steroids enhance neuronal excitability in $\mathrm{mPOA}^{\mathrm{Nts}}$ neurons}

Ovarian steroids not only altered the odor-encoding dynamics (Fig. 3), but also the basal and physiological properties of $\mathrm{mPOA}^{\mathrm{Nts}}$ neurons. Imaging spontaneous $\mathrm{Ca}^{2+}$ activity dynamics in intact cycling females across two days of the estrous cycle revealed that individual $\mathrm{mPOA}^{\mathrm{Nts}}$ neurons adjusted their spontaneous activity dynamics across hormonal states, specifically, showing enhanced $\mathrm{Ca}^{2+}$ activity on the afternoon of proestrus (when estradiol levels peak ${ }^{25}$ ) compared to the afternoon of estrus (Fig.S6i-1) and following estradiolpriming in ovariectomized females compared with vehicle (Fig.5a-d). To explore potential underlying physiological mechanisms, we performed ex vivo patch-clamp and fluorescent recordings from $\mathrm{mPOA}^{\mathrm{Nts}}$ neurons. We found that estradiol-priming increased the number of evoked action potentials (Fig.5e-f) and resulted in larger $\mathrm{Ca}^{2+}$ signals (Fig.S4a-c), compared with controls. $\mathrm{mPOA}^{\mathrm{Nts}}$ neurons also showed reduced action potential half-width and an increase in A-type $\mathrm{K}^{+}$channel conductance following estradiol replacement (Fig.5gh). This suggests that estradiol controls $\mathrm{mPOA}^{\mathrm{Nts}}$ excitability, at least in part by increasing the function of delayed rectifier $\mathrm{K}+$ channels, which rapidly repolarize the neurons to allow high frequency action potential generation. Collectively, these data illustrate how estradiol enhances the intrinsic excitability of $\mathrm{mPOA}^{\mathrm{Nts}}$ neurons that might permit for enhanced sensitivity to appetitive cues.

\section{Stimulation of $\mathrm{mPOA}^{\mathrm{Nts}}$-VTA neurons promotes reward and ventral striatal dopamine release in a steroid-responsive manner}

Appetitive cues excited $\mathrm{mPOA}^{\mathrm{Nts}}$ neurons and we next tested whether optogenetic activation of these neurons would convey positive valance signals and reinforce behavioral actions. We targeted $\mathrm{mPOA}^{\mathrm{Nts}}$ neurons with the light-gated cation channel, channelrhodopsin-2 (ChR2eYFP), and implanted optical fibers above the mPOA to permit for optogenetic stimulation (Fig. 6a-c). Intact female mice were tested for reward-related phenotypes across all four stages of the estrous cycle, as assessed by vaginal lavage ${ }^{26}$ (Fig. S7a). We observed that females readily nose poked to receive photostimulation of $\mathrm{mPOA}^{\mathrm{Nts}:: \mathrm{ChR} 2}$ neurons at multiple stimulation frequencies, and the number of nose pokes varied across the estrous cycle with the greatest number displayed in proestrus (Fig. 6d,e, Fig. S7b,c and Video 3). Photostimulation also produced a real-time place preference in $\mathrm{mPOA}^{\mathrm{Nts}:: \mathrm{ChR} 2}$ females across all four stages of the estrous cycle, but with cyclical changes in the magnitude of preference that were also higher in proestrus (Fig. 6f-h and Video 4). To test for potential sex differences in the rewarding effects of $\mathrm{mPOA}^{\mathrm{Nts}}$ stimulation, a cohort of males were tested under the same parameters. In contrast to females, photostimulation produced a more consistent real-time place preference across four consecutive days in $\mathrm{mPOA}^{\mathrm{Nts}:: \mathrm{ChR} 2}$ males, compared with mPOA ${ }^{\text {Nts::eYFP }}$ controls (Fig. 6i,j). In addition, photostimulation enhanced movement velocity in both male and females (Fig.S7d,e). We confirmed that this approach resulted in the activation of $\mathrm{mPOA}^{\mathrm{Nts}}$ neurons, as photostimulation induced Fos expression in $\mathrm{mPOA}^{\mathrm{Nts}: \mathrm{ChR} 2}$ mice but not $\mathrm{mPOA}^{\mathrm{Nts}:: \mathrm{eYFP}}$ controls (Fig.S8a-c). Collectively, these data demonstrate that stimulation of $\mathrm{mPOA}^{\mathrm{Nts}}$ neurons produces reinforcement in both sexes.

Although $\mathrm{mPOA}^{\mathrm{Nts}}$ neurons promoted reward-related phenotypes that varied in magnitude across the estrous cycle, it remained unclear whether steroids directly modulated these effects, and how these cells orchestrate the output of motivated behavior through recruitment 
of downstream circuit targets. $\mathrm{mPOA}^{\mathrm{Nts}: \mathrm{ChR} 2}$ assisted anterograde neuroanatomical tracing revealed dense fiber expression in the VTA from these cells (Fig. 7a), consistent with the identification of $\mathrm{mPOA}^{\mathrm{Nts}}$ cells as VTA-projecting neurons (Fig.1a,b). We then targeted optogenetic stimulation to either the PPOA $^{\text {Nts }}$ cell bodies or POA $^{\text {Nts }}$-VTA fibers before and after steroid-priming (estradiol and estradiol-progesterone) in ovariectomized female mice (Fig. 7a). Photostimulation of $\mathrm{mPOA}^{\mathrm{Nts}}$ cell bodies or $\mathrm{mPOA}^{\mathrm{Nts}}$-VTA fibers induced a modest real-time place preference in mice that was substantially amplified following estradiol replacement, but not after repeated stimulation under vehicle conditions (Fig.7c and S9a). Interestingly, this steroid-priming regimen of estradiol followed by progesterone, known to induce sexual receptivity ${ }^{27}$, resulted in a sustained increase in the reward effects of $\mathrm{mPOA}^{\mathrm{Nts}:: \mathrm{ChR} 2}$ stimulation for many consecutive weeks (Fig.S9a).

To determine whether activation of the $\mathrm{mPOA}^{\mathrm{Nts}}$-VTA pathway evoked mesolimbic dopamine release, we employed in vivo fast-scan cyclic voltammetry in anesthetized females and recorded dopamine release in the NAc (Fig. 7c). Photostimulation of $\mathrm{mPOA}^{\mathrm{Nts}}$-VTA fibers evoked dopamine release in the NAc that was greater in estradiol-primed females compared with controls (Fig. 7c-e). Together, these data indicate that $\mathrm{mPOA}^{\mathrm{Nts}}$ neurons promote rewarding phenotypes through interactions with mesolimbic dopaminergic circuits in the VTA. Further, these behavioral outputs as well as their physiological dopamine correlates were magnified in steroid-primed females; functionally identifying a molecularlydefined steroid-responsive reward pathway.

\section{Optogenetic modulation of $\mathrm{mPOA}^{\mathrm{Nts}}$ neurons regulates social attraction}

We next examined whether $\mathrm{mPOA}^{\mathrm{Nts}}$ neurons and their projections to the VTA are involved in social approach behavior toward a reproductive social stimulus. We measured attraction and preference for an intact male versus ovariectomized female stimulus in a social investigation assay, during alternating time epochs of photostimulation (see methods and Fig.8a). Time epochs were selected over proximity or zone related photostimulation parameters, since activation of this circuit reinforces behavior and could condition responses that might not be socially driven. Testing was conducted in the same females and males used as above (Fig.S9a-d). Photostimulation of $\mathrm{mPOA}^{\mathrm{Nts}: \mathrm{ChR} 2}$ neurons or the mPOA$\mathrm{VTA}^{\mathrm{Nts}:: \mathrm{ChR} 2}$ pathway enhanced male preference and increased the amount of time spent in the male social interaction zone, only in ChR2-expressing females previously treated with steroids (Fig.8b-e and Video 5). In males, photostimulation of mPOA ${ }^{\mathrm{Nts}:: \mathrm{ChR} 2}$ enhanced female preference and increased the amount of time spent in the female social interaction zone (Fig.S9b-d). Together, these data suggest that $\mathrm{mPOA}^{\mathrm{Nts}}$ neurons direct behavior toward opposite-sex conspecifics in both sexes to drive social attraction toward a potential mate.

Since steroids act to promote mate attraction in females ${ }^{21,28}$, we next tested whether endogenous activity of $\mathrm{mPOA}^{\mathrm{Nts}}$ neurons is required for sex-specific approach behavior in the presence of steroid-priming. Here, $\mathrm{mPOA}^{\mathrm{Nts}}$ neurons were targeted to express the inhibitory light gated chloride pump, halorhodopsin (NpHR), or control (eYFP) in ovariectomized female mice. Steroid-priming plus mating was necessary to first naturally elicit a male preference phenotype (Fig.S9e) as others have found ${ }^{21,29}$. Photoinhibition in steroid-primed (estradiol-progesterone) $\mathrm{mPOA}^{\mathrm{Nts}:: \mathrm{NpHR}}$ females impaired male preference 
and reduced male but not female investigation (Fig.8f-h and Fig.S9f). Since mate approach is facilitated by hormones and chemosensory cues ${ }^{21}$, we also tested male odor preference in steroid-primed females (Fig.8i) and found that photoinhibition of mPOA ${ }^{\text {Nts::NpHR }}$ neurons impaired behavioral preference for male urine (Fig.8j,k). It is unlikely that optogenetic modulation of these cells produced aversive effects that impaired social investigation, since photoinhibition did not produce a real-time place aversion in the presence or absence of steroid-priming (Fig.S9g). Finally, optogenetic modulation of $\mathrm{mPOA}^{\mathrm{Nts}}$ neurons did not affect palatable food consumption, although $\mathrm{mPOA}^{\mathrm{Nts}: \mathrm{ChR} 2}$ stimulation increased food zone approach bouts (Fig. S10a-0). This is in line with our in vivo imaging data, indicating that some mPOA $^{\text {Nts }}$ neurons are excited by food-related odors, versus male or female social odors (Fig. 4). Together, these experiments indicate that steroids enhance $\mathrm{mPOA}^{\mathrm{Nts}}$ neuronal function to facilitate approach behavior towards attractive social and nonsocial stimuli.

\section{Discussion}

Historically the mPOA has been considered an evolutionarily conserved region for social behaviors and homeostatic functions ${ }^{3,8}$. However, it has remained unclear whether mPOA circuitry orchestrates the appetitive and reinforcing aspects of social and non-social motivated behavior. Here, we provide evidence that mPOA-VTA ${ }^{\mathrm{Nts}}$ neurons covey positive valence signals, reinforce behavioral actions, and regulates ventral striatal dopamine release. It seems likely that mPOA-VTA ${ }^{\text {Nts }}$ fibers may directly inhibit VTA GABAergic neurons to promote motivation, given that the majority of $\mathrm{mPOA}^{\mathrm{Nts}}$ neurons project to the VTA, that these neurons are almost exclusively Vgat positive, and that VTA GABAergic neurons inhibit VTA dopamine neurons ${ }^{30-33}$. Thus, we speculate that activation of mPOA-VTA ${ }^{\mathrm{Nts}}$ fibers produces ventral striatal dopamine release via disinhibition of VTA dopamine neurons. Consistent with this, GABAergic VTA inputs, such as those from the lateral hypothalamus and bed nucleus of the stria terminalis (BNST), largely act to inhibit VTA GABA neurons to evoke dopamine release and promote reward-related behaviors ${ }^{34,35}$.

While we found that most $\mathrm{mPOA}^{\mathrm{Nts}}$ neurons project to the VTA, this comprised roughly a third of all mPOA-VTA projecting neurons (though viral targeting and retrograde tracing does not label every Nts or VTA projecting neuron). This suggests that other molecularlydefined mPOA subsets may have different encoding and behavioral properties compared to those described here. In the neighboring vBNST, GABAergic and glutamatergic VTAprojecting neurons differentially control rewarding and aversive motivational states, respectively ${ }^{34}$. Here, mPOA-VTA ${ }^{\mathrm{Nts}}$ stimulation promoted not only rewarding phenotypes, but also approach behavior toward an opposite-sex conspecific. Molecularly defined VTAprojection neurons might control distinct types of motivated behaviors (e.g., social, feeding, aversion), as well as different aspects of those behaviors (e.g., appetitive vs. consummatory). Using in vivo $\mathrm{Ca}^{2+}$ imaging, we found that some $\mathrm{mPOA}^{\mathrm{Nts}}$ neurons were engaged by multiple types of social stimuli but were unresponsive to appetitive non-social odor, and vice versa. This suggests that social versus nonsocial appetitive stimuli might recruit different neural ensembles within this mPOA reward circuit, and it is largely unclear whether different types of rewards are processed through distinct pathways within reward systems. In addition to distinctions between which neurons were excited, we observed variance in the magnitude of excitation in response to different odors within the same neurons. Different 
types of appetitive stimuli produced varying degrees of mPOA-VTA ${ }^{\mathrm{Nts}}$ circuit activation, with opposite-sex stimuli being the most potent activator, which might serve to promote and reinforce reproductive behaviors essential for species survival.

While male odor was the most robust modulator of $\mathrm{mPOA}^{\mathrm{Nts}}$ neural activity, is it is unknown whether this circuit is biased towards reproductive stimuli restricted to mating or if this extends to other forms of social stimuli relevant to offspring and species survival, such as infant cues. Here, a subset of $\mathrm{mPOA}^{\mathrm{Nts}}$ neurons co-expressed $\mathrm{Gal}$, which has previously served as a marker for mPOA neurons essential for parental behaviors in both male and female mice ${ }^{14}$. Maternal functions also require mPOA-VTA circuits ${ }^{4,6}$, but it is unknown whether the motivational aspects of mating and parenting share a common mPOA-VTA pathway that is appropriately tuned by hormonal profiles and social/reproductive experience or if there are distinct pathways for different social behaviors. Steroids including estrogen influence peptide hormones ${ }^{4}$, which influence mating and infant care through actions in the mPOA, putatively on VTA-projecting neurons ${ }^{4,6}$. Thus, a number of hormone/peptide and experience-induced changes could modify and tune this pathway in a context-specific manner. Mating and parenting induce distinct mPOA Fos activation patterns in male mice ${ }^{14}$, which could reflect the diversity of sensory and motoric aspects associated with different types of social interactions. Here, we restricted our imaging to different types of social and nonsocial odors, in order to rigorously differentiate between distinct salient stimuli processed through the same sensory modality. While less naturalistic, we used automated time-locked odor delivery in head-fixed mice to avoid movement interference, control the proximity and timing of the odor stimulus (rather than the mouse controlling it), and to allow for multiple trials to ensure consistency. Since females were more innately attracted to male odor stimuli over female stimuli, and male odor presentation produced the greatest activation of $\mathrm{mPOA}^{\mathrm{Nts}}$ neurons, this could reflect a bias towards the most motivating stimulus and/or relate to a male-specific sensory detection. In the present optogenetic tests, an opposite-sex behavioral preference was also detected, though it is possible that stimulation of this pathway might drive social approach towards other forms of social or same-sex stimuli in the absence of a competing potential mate. It also remains unknown which sensory or chemical components associated with detecting male odor were driving activation of this pathway. Compared with female urine, intact male urine contains a different profile of gonadal steroids ${ }^{21}$ and male-specific pheromone proteins including major urinary proteins, such as Darcin ${ }^{36}$, that promote mate attraction in female rodents. Future studies should utilize in vivo chronic imaging approaches from molecular and projection specific mPOA populations under a range of social and hormonal sex-specific contexts and following social experience.

The incentive value of particular stimulus is dependent on a number of internal physiological factors (e.g., hormonal levels and the homeostatic state of the animal) that are in constant flux. Here, $\mathrm{mPOA}^{\mathrm{Nts}}$ neurons adjusted their basal and evoked-odor activity dynamics across hormonal states. Multiple chemosensory inputs converge in the $\mathrm{mPOA}^{7,37}$, and our studies indicate that steroids prime social odor-sensing neurons to be more responsive to male signals. Estrogens can increase sensitivity to both chemosensory and auditory male cues ${ }^{21}$ and estrogen replacement in ovariectomized females decreases detection thresholds for male urinary odor ${ }^{38}$. A recent study used ex vivo $\mathrm{Ca}^{2+}$ imaging in female mice to reveal that 
vomeronasal sensory neurons detect attractive male pheromones in a steroid-sensitive manner ${ }^{39}$. Thus, steroids could be altering the processing of male stimuli at the multiple sites within the social brain network, through a number of mechanisms, which can be clearly delineated in future studies.

Our in situ data and other studies ${ }^{40}$ show that $\mathrm{mPOA}^{\mathrm{Nts}}$ neurons contain estradiol receptors (ESR1). Steroids including estradiol can induce slower genomic actions through binding of nuclear steroid receptors that act as transcription factors to promote or repress gene expression in the hypothalamus ${ }^{41}$. Here, estradiol enhanced $N t s$ and VGat mRNA in mPOA neurons, though since the Nts promoter lacks palindromic estrogen response elements, estradiol likely increased Nts mPOA expression through a PKA-dependent signaling pathway, as others have found ${ }^{18}$. Estradiol can also exert rapid non-genomic actions through acting at membrane-bound receptors or ion-channels, that stimulate intracellular signaling pathways and can increase or decrease cell excitability ${ }^{42,43}$. Indeed, we showed that estradiol enhanced the intrinsic excitability of $\mathrm{mPOA}^{\mathrm{Nts}}$ neurons in part by increasing delayed rectifier $\mathrm{K}^{+}$channel conductance, thus preventing action potential amplitude attenuation and failure. In agreement with our slice data, estradiol-priming prior to imaging enhanced $\mathrm{Ca}^{2+}$ dynamics, which were characterized by elevated event amplitude and duration. Since, steroids were administered hours and days prior to preparing tissue for slice electrophysiological recordings or examining behavioral and neuronal encoding, this time frame permits for slower genomic actions that alter the expression of genes, receptors, or ion channels. It is also possible that prior in vivo estradiol altered the expression of $\mathrm{K}^{+}$channels as seen in the arcuate nucleus ${ }^{44}$, and/or that ex vivo estradiol in the bath, for electrophysiological recordings, directly affected $\mathrm{K}^{+}$channel activity ${ }^{42}$.

Apart from estradiol, a number of other steroid and peptide hormones could also orchestrate the activity of this circuit in male and females. Here, estradiol was sufficient to enhance responsiveness to male odor cues and amplify the rewarding effects of mPOA-VTA ${ }^{\mathrm{Nts}}$ photoactivation and dopamine release in the ventral striatum. In line with our findings, other studies identified that mPOA-VTA projections from the mPOA contain estrogen receptors (membrane-bound and nuclear) and estradiol administration restricted to the MPOA enhanced drug-induced ventral striatal dopamine release ${ }^{12,13}$. Estradiol can also increase expression of progesterone receptors and these steroids act in combination to induce sexual receptivity in rodents ${ }^{45}$. However, we did not disentangle between contributing effects of estradiol and progesterone or identify which types of receptors were mediating the observed outcomes. Future studies should identify how different hormones and their underlying mechanisms influence the processing of social and nonsocial salient signals by mPOA neurons.

\section{Conclusions}

Here, we implement a multifaceted approach in order to disentangle in vivo neural encoding properties and circuit functions modulated by different hormonal contexts. Further, these studies suggest that neural networks excited by social signals are embedded within valenceprocessing circuits and can directly orchestrate motivational states. While many studies have used in vivo circuit strategies to study social or motivated behaviors, our understanding of 
how positive and negative valence circuits are intertwined with social networks is in its infancy. Our future studies will continue to use circuit strategies in conjunction with in vivo imaging to resolve whether precise neurons encode with reward-type specificity and whether the same networks integrate not only different types of rewarding stimuli, but also aversive signals that could underlie complex interactions between stress, social functioning, and reward-related deficits.

Collectively, these studies demonstrate how hormonal signals fine-tune neural circuit dynamics at key reproductive network nodes to translate sensory input into socially-directed motivated behavior essential for species survival. Uncovering neural circuits that function to bridge social and reward processing will provide important insights for social and affective disorders. Moreover, while steroid-mediated shifts in neural processing are generally adaptive for reproductive strategies, such actions can destabilize mood in some women ${ }^{46,47}$ and contribute to hormonal and sex-related influences in drug addiction ${ }^{48,49}$. Further elucidation of steroid-sensitive circuits that control motivational states may provide novel therapeutic targets for sex-biased psychiatric and reproductive mood disorders.

\section{Online methods}

\section{Animals and Surgeries}

Subjects-Nts-IRES-Cre mice ${ }^{1}$ were maintained and Nts-Cre or wild type littermate mice were group housed according to sex (20-30g; 6-9 weeks old) until surgery or behavioral testing. Mice were maintained on a reverse 12-hr light cycle (lights off at 07:00) with ad libitum access to food and water. All procedures were conducted in accordance with the Guide for the Care and Use of Laboratory Animals, as adopted by the NIH, and with approval of the Institutional Animal Care and Use Committee at the University of North Carolina at Chapel Hill (UNC).

Subject history-All wild-type animals were randomly assigned to groups. In cases of experiments with transgenic mice, groups requiring the presence or absence of Cre were determined by the genotype of the mouse and then randomly distributed. Animals were naïve to experimental testing before being assigned to a study. Optogenetic behavioral modulation experiments were conducted with the following cohorts of animals and tested under specified assays. Intact females for optogenetic activation were tested across the estrous cycle for the real-time place preference and optical self-stimulation. Intact males for optogenetic activation were tested for real-time place preference and social approach behavior. Ovariectomzied females for optogenetic activation were tested for real-time place preference, social approach assay, and high-fat diet assay. Ovariectomzied females for optogenetic inhibition were tested for real-time place preference, social approach assay, high-fat diet assay, and odor preference.

General procedures-For all surgeries descried below, mice were anesthetized with 0.8 $1.5 \%$ isoflurane mixed with pure oxygen $(1 \mathrm{~L} / \mathrm{min})$ and placed within a stereotactic frame (David Kopf Instruments) and all surgical instruments and materials were sterilized. Ophthalmic ointment (Akorn) and a topical anesthetic (2\% Lidocaine; Akorn) were applied during surgeries, and subcutaneous injections of sterile saline $(0.9 \% \mathrm{NaCl}$ in water) were 
administered to prevent dehydration. Following surgeries, mice received acetaminophen in their drinking water for two days and were monitored for 7 days or until full recovery.

Viral Constructs-Cre-inducible AAV5-EF1a-DIO-hChR2(H134R)-eYFP; 4.3×10 12 infectious units/mL, AAV5-EF1a-DIO-eYFP; 6.0 $\times 10^{12}$ infectious units $/ \mathrm{mL}$, and AAV5EF1a-DIO-eNpHR3.0-eYFP; 6.0×10 ${ }^{12}$, AAVdj-EF1a-DIO-GCaMP6s; $3.1 \times 10^{12}$ infectious units $/ \mathrm{mL}$; were packaged by the UNC vector core and delivered stereotaxically in the mPOA of anesthetized mice.

Viral and Optogenetic Surgery-For all virus surgeries for optogenetics, slice physiology, or anatomical tracing, animals were anesthetized and treated as described above. Bilateral injections of Cre-inducible virus ( $500 \mathrm{nl} / \mathrm{side})$ was administered at a $10^{\circ}$ angle into the mPOA (relative to bregma: AP, $+0.15 \mathrm{~mm}$; ML, $\pm 1.30 \mathrm{~mm}$; DV, $-5.10 \mathrm{~mm}$ ). For retrograde anatomical tracing, Red Retrobeads (Lumafluor) were bilaterally injected (300 nl/ side) at a $10^{\circ}$ angle into the VTA (relative to bregma: AP, $-3.12 \mathrm{~mm}$; ML, $\pm 1.30 \mathrm{~mm}$; DV, $-5.0 \mathrm{~mm}$ ). For optogenetic surgeries, custom-made chronic optical fibers ${ }^{2}$ were also implanted bilateral at a $10^{\circ}$ angle $\sim 0.50 \mathrm{~mm}$ above the mPOA or VTA target site relative to the coordinates listed above. For behavioral experiments targeting optogenetic stimulation to the mPOA or VTA the same mice were used and fibers were implanted in both regions. Following surgery, we allowed sufficient time for viral infection and transgene expression. The time course between viral injections and the start of experiments was $4-6$ weeks for optogenetic cell body manipulations and ex vivo slice physiology and $7-8$ weeks for optogenetic terminal manipulations.

GRIN Lens Surgery-For deep-brain in vivo two-photon calcium $\left(\mathrm{Ca}^{2+}\right)$ imaging experiments, animals were anesthetized as described above and the cre-inducible genetically encoded $\mathrm{Ca}^{2+}$ indicator GCaMP6s ${ }^{3}$, was unilaterally injected into the mPOA (500 nl at $2 \mathrm{D}$ $\mathrm{V}$ axes; relative to bregma: AP, $+0.05 \mathrm{~mm}$; ML, $\pm 0.25 \mathrm{~mm}$; DV, -4.95 and $-5.15 \mathrm{~mm}$ ). Prior to injections, the craniotomy site was carefully prepared and tissue aspirated within minimal bleeding ${ }^{4}$. Then a gradient-refractive index (GRIN) lens $(7.3 \mathrm{~mm}$ length, $0.6 \mathrm{~mm}$ diameter, Inscopix GLP-0673) was slowly stereotaxically lowered to a location directly above the mPOA at different coordinates than the viral injection site (relative to bregma AP, $+0.10 \mathrm{~mm}$; ML, $\pm 0.35 \mathrm{~mm}$; DV, $-4.75 \mathrm{~mm}$ ) to avoid placing the lens in the immediate area of the injection track that typically exhibits autofluorescence that could interfere with imaging. Lastly, a custom-made ring (stainless steel; $5 \mathrm{~mm}$ ID, $11 \mathrm{~mm}$ OD) was attached to the skull during surgery to allow for subsequent head fixation (see Figure 5a). Animals were monitored for GCaMP6 expression 4 weeks after surgery using 2-photon microscopy as described below and only those with dynamic GCaMP6 expression in at least 50 cells and absent of autofluorescence were used for imaging experiments.

Ovariectomy and hormone replacement-Females were anesthetized as described above and ovariectomized through bilateral flank incisions. The ovary was located in a fat pad just beneath the muscles and using forceps, the periovarian fat was gently grasped to lift and exteriorize the ovary. The uterine horn was then returned into the abdomen and the process repeated on the other side. The muscle of the posterior abdominal wall was then 
sutured and the exterior skin incision closed with sterile surgical staples. Mice were monitored daily following surgery and staples were removed a week later. Females recovered for at least 10 days prior to testing. Estradiol was administered at $10 \mu \mathrm{g}$ and progesterone at $500 \mu \mathrm{g}$ in $0.05 \mathrm{ml}$ of sesame oil delivery s.c. and 48 hours apart since this regimen referred to as steroid priming has been shown to induce sexual receptivity and these levels of estradiol are comparable to physiological proestrus peak levels ${ }^{5-7}$. Vehicle injections consisted of $0.05 \mathrm{ml}$ of sesame oil. Behavioral testing or physiological recordings were all conducted approximately $4-5$ hours after the injection.

\section{Estrous cycle monitoring}

Female mice are spontaneous ovulators and typically have a 4-6 day estrous cycle that consists of four stages - proestrus, estrus, diestrus I/metestrus, and diestrus/II. Mice were habituated to handling and vaginal smears prior to the behavioral experiments. Before 09:00 hours, mice were swabbed daily regardless of behavioral testing to check for consistent cycling ${ }^{8,9}$ and underwent behavioral testing in the afternoon between $1300-1700$ hours. Using a disposable pipette, a small volume of physiological sterile saline was placed near the opening of the vagina and $100 \mathrm{ul}$ of saline was flushed in four repetitions without insertion to avoid pseudopregnancy. The smear was displaced onto a glass slide and immediately examined under a brightfield microscope at 20x. The identification of estrous stages was based on characteristic cell type appearance observed and the density of each cell type in the vaginal secretion. Estrous stage was identified by changes in cell type across the cycle that reflects circulating gonadal steroids. Note that "estrus" does not refer to "behavioral estrus" or the state of being sexually receptive. Females were only tested for behavior on days when a clear smear was visible and the cycle stage could easily be identified. In cases where a smear was unclear or an animal did not resume the anticipated estrous stage following optogenetic or behavioral stimulation, the animal was not tested until resuming consistent estrous cycling.

\section{Behavioral Optogenetics}

General Procedures for Light Delivery-Prior to behavioral testing, animals were habituated to handling and patch cable tethering in their home cage for at least four habituation sessions lasting $\sim 10$ minutes. For optogenetic manipulations, light $\sim 10 \mathrm{~mW}$ from diode pumped solid-state lasers ( $473 \mathrm{~nm}$ or $532 \mathrm{~nm}$ ) was delivered through custom-made patch cables attached to the implanted chronic fibers on animals' head as described previously ${ }^{10,11}$. For photoactivation, $473 \mathrm{~nm}$ light was pulsed at $20 \mathrm{~Hz}$ with a pulse width of $5 \mathrm{~ms}$. For photoinhibition experiments, $532 \mathrm{~nm}$ light was constantly delivered. Animals were able to freely move within the testing chambers with little hindrance and all behavioral testing was conducted under red incandescent lighting between 13:00 and 18:00 hours. For each behavioral assay, Ethovision or MedPC software and Arduino microcontrollers were used to control light delivery parameters through a TTL pulse.

Behavioral testing: schedule relative to hormone contexts-For intact cycling experiments, females were not run more than twice a week, to avoid disruption of the natural cycle. Females were smeared in the morning and behavior was tested in the afternoon as described above (Estrous cycle monitoring). For all hormone manipulation experiments in 
ovariectomzied females, animals were tested $\sim 4-5$ hours after injections as described above (Surgery - Ovariectomy and hormone replacement.).

Behavioral Testing: reward and feeding assays-For real-time place preference testing, subjects controlled the amount of light stimulation as determined by their center point location within the testing area in 20 min sessions. For optical self-stimulation, animals were given access to an active and inactive port and could nose poke to receive optical stimulation over a $30 \mathrm{~min}$ test period. For additional details on these behavioral assays $\mathrm{se}^{10}$. For optogenetic manipulation during a free-feeding assay, animals were given access to a high-fat food and consumption measured as previously described ${ }^{12,13}$.

Behavioral Testing: social and odor preference assays-For optogenetic manipulations during a social preference assay, subjects were placed in a standard 3chamber social choice arena ${ }^{14}$ but instead two social stimuli were used in our paradigm (see Figure 8a). Stimulus mice were previously habituated to the holding chambers for at least 3 days prior to experimental testing. For female test subjects a wild type intact adult male or ovariectomized female stimulus mouse was placed into each of the social interaction holding chambers. For male test subjects, a hormone-primed ovariectomized female or adult male was used. Subjects were first habituated to the area in the absence of light delivery or social stimuli and screened for any innate side preference to the area. Light delivery occurred in alternating $5 \mathrm{~min}$ epochs for a total of $20 \mathrm{~min}$. For NpHR cohorts, hormone-primed females were first mated in their home-cage to induce a male preference prior to behavioral testing. Since we observed reinforcing properties in response $\mathrm{mPOA}^{\mathrm{Nts}}$ stimulation, we used optogenetic modulation parameters that were not time-locked to occur with social proximity, since pairing could artificially condition and reinforce approach behavior.

For odor preference testing, subjects were placed into a rectangular arena and testing lasted for $20 \mathrm{~min}$ with light delivery alternated in $5 \mathrm{~min}$ epochs. Subjects were first habituated to the area for $10 \mathrm{~min}$ and screened for any innate side preference. Then, two square blocks placed on opposite walls of the arena tightly held either a cotton swab containing urine or physiological saline (60 ul per swab). See Figure 8 i for graphical depiction. Wild type stimulus mice were habituated to a chamber containing a wire mesh floor without bedding and a drip pan for the collection of fresh mouse urine. Urine was pooled from 4 group housed male mice and 1 single housed adult male, since male urine contains femaleattracting proteins (e.g. Darcin ${ }^{15}$ ) which are variable in expression across mice and can be influenced by social environment ${ }^{16}$. Female urine was pooled from 5 ovariectomized grouphoused females. Peanut oil was used at full strength and (60 ul per swab) during testing. Peanut oil was first applied to a piece of food in the homecage the day prior to behavioral testing or imaging odor-evoked responses.

Behavioral Analysis-All behavioral experiments were recorded live with a video camera and PC equipped with live tracking software (Noldus, Ethovision XT). Automated measures of movement (velocity and distance) and the frequency and duration of time spent in each designated zone of the area was generated based on live tracking Ethovision software and calculated with respect to light condition. Preference indices for social or food stimuli 
were computed based on these metrics as previously described ${ }^{17}$. Food consumption was manually scored with assisted software (Noldus, Observer).

\section{Two-photon in vivo Calcium Imaging}

Head-fixed Imaging-To visualize $\mathrm{Ca}^{2+}$ dynamics in vivo, GCaMP6s was expressed in $\mathrm{mPOA}^{\mathrm{Nts}}$ neurons and a GRIN lens implanted to gain optical access to this deep brain region as described above (see Lens Surgery). Mice were habituated to head-fixation for at least 4 non-consecutive days with increasing time intervals (5 - $30 \mathrm{~min})$ and then two-photon microscopy was used to visualize activity dynamics of $\mathrm{mPOA}^{\mathrm{Nts}}$ neurons in vivo. The last habituation session occurred in conjunction with two-photon imaging to select a particular field of view (FOV) by adjusting the imaging plane (z-axis) to select a different group of cells across multiple FOVs within each subject. Multiple FOVs were collected for baseline / spontaneous imaging sessions and a single FOV with the most cells was chosen for stimulus odor-evoked imaging sessions (to avoid time confounds).

Imaging: schedule relative to hormone contexts-Females were not imaged more than twice a week, to avoid disruption of the natural cycle. Females were smeared in the morning (see Estrous cycle monitoring) and imaging was conducted in the afternoon as described above. For all hormone manipulation experiments in ovariectomzied females, mice were imaged $\sim 45$ hours after injections as described above (for more hormone details see Surgery - Ovariectomy and hormone replacement.).

Spontaneous $\mathrm{Ca}^{2+}$ Activity-To examine spontaneous $\mathrm{Ca}^{2+}$ events across hormonal states, females were smeared (intact females) or injected (ovariectomized females) before 09:00 hours and $\mathrm{mPOA}^{\text {Nts::GCaMP6 }}$ cells imaged in vivo $\sim 4$ hrs later. Baseline scans from each FOV were acquired for $10 \mathrm{~min}$ at $5 \mathrm{~Hz}$ as described below.

Odor-evoked $\mathrm{Ca}^{2+}$ Activity-For odorant delivery, fresh urine was collected using the same 5 male or female animals that were group-housed and urine was pooled together (see Behavioral Optogenetic Methods), since there are individual differences in the amount of proteins in male urine that attract the female mice. Urine was collected from the same stimulus mice were used across all imaging studies to ensure consistency within and between mice. Mouse urine from each sex or peanut oil was added to a chamber and vaporized through an airflow tank similar to room air and flowed out through a mask placed in front of but not touching the animal's snout and a vacuum line on the adjacent side to remove any residual odor. Specifically, 160 ul of Urine diluted in dipropylene glycol was placed into a small chamber and odorants were delivered using a custom-made olfactometer. Medical air (2L/min) served as positive pressure that led to a mask situated in front of the subject's snout with a vacuum line to help remove any residual odor (See Fig. 2a). To time odorant delivery during imaging, a microcontroller was programmed to initiate imaging and trigger a solenoid that switched from air to the odor tank. During each imaging session, twophoton scanning was triggered for each trial $10 \mathrm{~s}$ before odorant delivery, and a $40 \mathrm{~s}$ video was collected for each trial. Each odorant trial was delivered in 6-7 repetitions with a 2-3min inter-trial interval to avoid odor habituation. 
Two-photon Imaging acquisition-A two-photon Olympus microscope (FVMPE-RS) was equipped with the following: a hybrid scanning core set with galvanometers and fast resonant scanners (allows up to $30 \mathrm{~Hz}$ frame-rate acquisition; set to $5 \mathrm{~Hz}$ ), GaAsP-PMT photo detectors with adjustable voltage, gain, and offset, a long working distance 20× air objective designed for optical transmission at infrared and visible wavelengths (Olympus, LCPLN20XIR, 0.45NA, 8.3mm WD), a software-controlled modular XY stage loaded on a manual z-deck, and a tunable Mai-Tai Deep See laser with dispersion compensation (Spectra Physics, laser set to $955 \mathrm{~nm}, \sim 100 \mathrm{fs}$ pulse width) with automated four-axis alignment. Data were both acquired and processed using a computer equipped with FluoView (Olympus, FV1200) software. For all sessions, time series images of $\mathrm{mPOA}^{\mathrm{Nts}: \mathrm{GCaMP} 6}$ cells were collected using the resonant scanner at $30 \mathrm{~Hz}$ with 6 frame on the fly frame averaging, which permits for final image acquisition at $5 \mathrm{~Hz}$. Software acquisition settings were optimized for each subject and set within the following range; Laser intensity: less than $\sim 50 \mathrm{~mW}$, PMT voltage: $650-675$, Gain: 1.5, Offset: 2, Scan Size: $512 \times 512$, Zoom 1-1.5, Aspect Ratio: 1:1. For chronic imaging experiments the same FOV was acquired under the same imaging parameters and software acquisition settings across all days for comparison.

Data extraction and analysis-Following acquisition, data were exported as a tiff series and motion corrected using a planar hidden Markov model (SIMA v1.3; ${ }^{18}$ ) and regions of interest (ROIs) were hand drawn around each cell or dendrite on the standard deviation projection tiff image of the motion-corrected video using ImageJ. For chronic imaging experiments, the same ROI series file was loaded onto the tiff image and individual ROIs were adjusted to ensure proper alignment with each cell and only cells that could be reliably identified at the same FOV were included in subsequent analysis. Next, normalized calcium signals were then extracted from the ROIs using the SIMA objects and motion corrected imaging video and all subsequent analyses were conducted using freely-available Python packages (SIMA, numpy, scipy, pandas, seaborn). All analysis code can be found at www.gitub.com/stuberlab.

Event detection-For each ROI, extracted fluorescence intensity time series data were independently z-scored and then smoothed with a 3-frame rolling mean. Using the normalized and smoothed time series data, calcium transients were defined as events if the transient magnitude exceeded 1 standard deviation for at least 5 frames $(1 \mathrm{~s})$. The start and end of each event were defined as the points at which the normalized signal crossed the 1 standard deviation threshold, and the duration of each event was calculated using these boundaries. The peak amplitude was the maximum normalized intensity value within each event. For the rare instances in which acquisition started or ended during an ongoing calcium event, that event was removed from all subsequent analyses.

Detecting Odor-evoked Responses-Analyses were performed on SIMA-corrected fluorescence intensity time series data. For each ROI and each trial, normalized intensity values were calculated by dividing each value by the mean intensity of the baseline epoch (10 s immediately preceding odor presentation). Cell responsivity was assessed for each cell using the Wilcoxon signed-rank test across 6-7 trials per session. Mean baseline fluorescence was compared to the mean fluorescence during the odor epoch. Excited ROIs 
were those in which the odor response was significantly $(\mathrm{p}<0.05)$ greater than baseline, and inhibited ROIs were those in which the odor response was significantly $(\mathrm{p}<0.05)$ lower than baseline. The number of trials was consistent for each experiment (Fig. 2: 6 trials, Fig. 3 and 4: 7 trials) and all odor trials were included in the analysis for all subjects and all ROIs.

\section{in vivo Fast-scan Cyclic Voltammetry}

Fast-scan cyclic voltammetry (FSCV) experiments were conducted using method described in previous studies ${ }^{19,20}$. Briefly, mice were anesthetized and placed in a stereotaxic frame. A craniotomy was done above the nucleus accumbens (AP, $+1.0 \mathrm{~mm}$; ML, $1.0 \mathrm{~mm}$ ) and the VTA (AP, $-3.1 \mathrm{~mm}$; ML, $0.3 \mathrm{~mm}$ ). An $\mathrm{Ag} / \mathrm{AgCl}$ reference electrode was implanted in the contralateral forebrain. An optical fiber $(200 \mu \mathrm{m})$ was placed for the activation of ChR2expressing VTA neurons (DV, from -4.0 to $-4.6 \mathrm{~mm})$. A carbon fiber electrode ( $100 \mu \mathrm{m}$ in length, $6 \mu \mathrm{m}$ diameter) for voltammetric recordings was then lowered into the nucleus accumbens (DV, from -4.0 to $-4.6 \mathrm{~mm}$ ) in $0.2 \mathrm{~mm}$ intervals. Voltammetric measurements were made every $100 \mathrm{~ms}$ by application of a triangle waveform $(-0.4 \mathrm{~V}$ to $+1.3 \mathrm{~V}$ to $-0.4 \mathrm{~V}$ vs. $\mathrm{Ag} / \mathrm{AgCl}$, at $400 \mathrm{~V} / \mathrm{s}$ ) to the carbon fiber electrode. Dopamine release was evoked by optical activation mPOA to VTA fibers using a 60 pulse-stimulation $(5 \mathrm{~ms}$ single pulse duration) at $20 \mathrm{~Hz}$. Therefore, optical stimulation of ChR2-expressing VTA fibers was applied for $3 \mathrm{~s}$ starting $5 \mathrm{~s}$ after the onset of the voltammetric recording. Recorded voltammetric signals showed an oxidation peak at $+0.65 \mathrm{~V}$ and a reduction peak at $-0.2 \mathrm{~V}$ (vs. $\mathrm{Ag} / \mathrm{AgCl}$ reference), as well as characteristic cyclic voltammograms, ensuring that the released chemical was dopamine. Carbon fiber electrodes were calibrated in vitro with known concentrations of dopamine $(1.0$ and $5.0 \mu \mathrm{M})$. Calibrations were done in duplicate and the average value for the current at the peak oxidation potential was used to normalize in vivo signals to dopamine concentration. All voltammetry data were collected and analyzed using TarHeel CV software.

\section{Patch-clamp electrophysiology}

Mice were anesthetized with pentobarbital $(50 \mathrm{mg} / \mathrm{kg}$ ) before transcardial perfusion with ice-cold sucrose cutting solution containing the following (in mM): 225 sucrose, $119 \mathrm{NaCl}$, $1.0 \mathrm{NaH}_{2} \mathrm{PO}_{4}, 4.9 \mathrm{MgCl}_{2}, 0.1 \mathrm{CaCl}_{2}, 26.2 \mathrm{NaHCO}_{3}, 1.25$ glucose, $305 \mathrm{mOsm}$. Brains were then rapidly removed, and coronal sections $300 \mu \mathrm{m}$ thick were taken using a vibratome (Leica, VT 1200). Sections were then incubated in $\operatorname{aCSF}\left(32^{\circ} \mathrm{C}\right)$ containing the following (in $\mathrm{mM}$ ): $119 \mathrm{NaCl}, 2.5 \mathrm{KCl}, 1.0 \mathrm{NaH}_{2} \mathrm{PO}_{4}, 1.3 \mathrm{MgCl}, 2.5 \mathrm{CaCl}_{2}, 26.2 \mathrm{NaHCO}_{3}, 15$ glucose, $305 \mathrm{mOsm}$. After an hour of recovery, slices were constantly perfused with $\mathrm{aCSF}\left(32^{\circ} \mathrm{C}\right)$ and visualized using differential interference contrast through a 40× water-immersion objective mounted on an upright microscope (Olympus BX51WI). Whole-cell recordings were obtained using borosilicate pipettes (3-5 $\mathrm{M} \Omega$ ) back-filled with internal solution containing the following (in mM): $130 \mathrm{~K}$ gluconate, $10 \mathrm{KCl}, 10 \mathrm{HEPES}, 10 \mathrm{EGTA}, 2 \mathrm{MgCl}_{2}, 2$ ATP, 0.2 GTP (pH 7.35, 270-285 mOsm).

We performed whole-cell current-clamp recordings of fluorescently-labeled mPOA ${ }^{\text {NTS:eYFP }}$ neurons or $\mathrm{mPOA}^{\mathrm{NTS}: G C a M P 6 s}$ neurons to characterize the intrinsic excitability of $\mathrm{mPOA}^{\mathrm{NTS}}$ neurons ex vivo ${ }^{21}$. During recordings, cells were held through slow polarization at $-70 \mathrm{mV}$ to control for differences in resting membrane potential between neurons. Next, we 
measured rheobase (the minimum amount of current required for an action potential to fire) by applying a series of short depolarizing sweeps $(50 \mathrm{~ms}$ ) at $+5 \mathrm{pA}$ steps (starting at $0 \mathrm{pA}$ ) until the recorded neuron fired an action potential. Next, action potential firing was examined by applying a series of $800 \mathrm{~ms}$ depolarizing sweeps from 0 to $160 \mathrm{pA}(+10 \mathrm{pA}$ steps for excitability recordings, $+20 \mathrm{pA}$ steps GCaMP6s recordings). For GCaMP6s experiments, during patch-clamp recordings we simultaneously recorded GCaMP6s fluorescence through a microscope-mounted camera (OptiMos, QImaging) using imaging software (MicroManager, ImageJ). Videos were subsequently motion-corrected if necessary, and data were extracted using ImageJ.

We also performed whole-cell voltage clamp recordings of fluorescently-labeled $\mathrm{mPOA}^{\mathrm{NTS}}$ eYFP neurons to measure $\mathrm{K}^{+}$channel conductance ex vivo. Recordings were performed in the presence of the voltage-gated sodium channel antagonist tetrodotoxin $(500 \mathrm{nM})$, the nonselective voltage-gated potassium channel antagonist 4-aminopyradine (20 $\mathrm{uM})$, and the $\mathrm{GABA}_{\mathrm{A}}$ receptor antagonist picrotoxin $(100 \mathrm{uM})$. During recordings, cells were held at $-80 \mathrm{mV}$ before $100 \mathrm{~ms}$ depolarization ( 0 to $110 \mathrm{mV},+10 \mathrm{mV}$ steps). A-type potassium current was then quantified by dividing the slower current deflections by the fast capacitive transient $(\mathrm{pA} / \mathrm{pF})$. For all patch-clamp experiments, data acquisition occurred at 1 $\mathrm{kHz}$ sampling rate through a MultiClamp 700B amplifier connected to a Digidata 1440A digitizer (Molecular Devices). Data were quantified using event analysis in Clampfit 10.3 (Molecular Devices).

\section{FSCV and patch clamp recordings and in situ: schedule relative to hormone} contexts-For all experiments, ovariectomzied females were given an initial dose of estradiol or vehicle 48 prior to a second dose and were euthanized $\sim 4-5$ hours after the last injections as described above (Surgery - Ovariectomy and hormone replacement.). This schedule was used to allow ample time for both genomic and non-genomic steroid actions $^{22,23}$ and was used in prior physiology studies ${ }^{24,25}$. For patch clamp experiments, 1 $\mathrm{uM}$ of estradiol was also applied to the bath solution for brain slices from mice previously treated with estradiol in vivo.

\section{Fluorescent in situ Hybridization}

Tissue was processed using in situ hybridization to detect mRNA for Nts, Vgat (Slc32a1), and Vglut2 (Slc17a6). Mice were briefly anesthetized with 3.5 - 4.0\% isoflurane mixed with pure oxygen $(1 \mathrm{~L} / \mathrm{min})$, rapidly decapitated and brains rapidly extracted and flash frozen on dry ice. 18- $\mu \mathrm{m}$ thick cryostat coronal sections were collected under RNAse-free conditions, fixed in $4 \%$ PFA for $15 \mathrm{~min}$ at $4{ }^{\circ} \mathrm{C}$, dehydrated in serial concentrations of ethanol $(50 \%-$ $100 \%$ ), and processed according to the protocol provided in the RNAscope kit (Advanced Cell Diagnostics. INC, Cat. 320 293). Sections were hybridized with the following mixed probes; Nts (Mm-Nts, Cat. 420441), Vgat (Mm-Slc32a1, Cat. 319191), and Vglut2 (MmSlc17a6-C2, 319171), for $2 \mathrm{~h}$ at $40^{\circ} \mathrm{C}$ and following amplification, sections were counterstained with DAPI. For Nts and Cre, were performed in situ using the Affymetrix View RNA 2-Plex Tissue Assay Kit with custom probes for Nts (Mouse NM024435, Cat. VB1-16908) and Cre (Vector, HQ335171 Cat.designed by Affymetrix (Santa Clara, CA). 


\section{Immunohistochemistry and Histology}

To evaluate optically evoked Fos, mice received 10 min of photostimulation in the home cage $(473 \mathrm{~nm}, 20 \mathrm{~Hz}$ at $3 \mathrm{~s})$ and were euthanized an hour later. Mice were euthanized with pentobarbital $(50 \mathrm{mg} / \mathrm{kg}$, i.p.) and transcardially perfused with $0.01 \mathrm{M}$ phosphate buffered saline (PBS) followed by $4 \%$ paraformaldehyde (PFA). Tissue was post-fixed overnight at $4{ }^{\circ} \mathrm{C}$ in PFA and cyroprotected in 30\% sucrose in PBS and 40- $\mu \mathrm{m}$ thick cryostat coronal sections were collected. To examine Fos induction, immunohistochemistry was carried out using the following antibodies: c-Fos primary raised in goat (Santa Cruz, cat\# SC-52g, 1:500 over night at $4{ }^{\circ} \mathrm{C}$ ) and secondary (Jackson Immuno, donkey anti-goat 6472 hours at room temperature) and processed as previously described. For TH staining TH primary raised in sheep was used (Pel-Freeze, cat\#PG0101-150, 1:500 over night at $4^{\circ} \mathrm{C}$ ). Tissue slices were slide mounted, DAPI counterstained, and coverslipped for subsequent confocal microscopy. For all other optogenetic behavioral cohorts and anatomical tracing experiments, mice were euthanized and tissue prepared as described (with the exception of IHC) for verification of viral expression and fiber placement. For in situ cohorts examining the effects of estrogeninduced Nts mRNA the tissue was processed in duplicate and the same pattern was observed upon replication. For verification of viral expression, all subjects were included in analyses unless post-hoc examination of tissue did not confirm the expected viral expression (e.g., ChR2, eYFP). This was the case for 2 mice and these subjects were removed from the analyses because the procedure is not valid without the proper viral expression. This exclusion criteria was established prior to conducting any of the present studies.

\section{Confocal Microscopy}

Images were captured with a confocal microscope (Zeiss LSM 780, Germany) and Zen software with a $20 \times$ air and $40 \times$ or $63 \times$ oil objective. Software settings were optimized for each experiment, but generally z-stacks were collected in less than $1 \mu \mathrm{m}$ increments throughout the z-axis and the maximum intensity projection tiled image was used for representative or quantification purposes.

\section{Protein and mRNA Quantification}

For quantification of mPOA cells expressing Fos protein or Nts mRNA, an experimenter blind to the treatment group manually tagged cells using Image $\mathbf{J}$ and the Image $\mathbf{J}$ Cell Counter Plug-in. For quantification of mRNA intensity, an experimenter blind to the treatment condition drew ROIs of the same size around each cell within a single focal plane on the DAPI layer. Then intensity of mRNA expression within each ROI was automatically generated in Image J. These values were then used to determine if intensity crossed a threshold that designated the cell as positive for the gene of interest (e.g. Nts) and whether Nts positive cells co-expressed Vgat or Vglut2.

\section{Experimental blinding}

In all experiments, data were analyzed in an automated unbiased manner by a computer. For in vivo imaging and physiology data, Software or custom written Python codes were used to automate data analysis. The investigator was not blind to within group drug treatment, as it was necessary to administer the appropriate drug (e.g., hormone or vehicle) with respect to 
day or subject. The experimenter was also not blind to the odor treatment, as it was necessary to delivery the appropriate odor.

\section{Statistics}

The number of biological replicates in each experiment was at least 3 mice per group for anatomy, $4-8$ mice per group for in vivo imaging or physiology, and between 5-7 mice per group for behavior. These numbers were chosen based on that used in previous experiments ${ }^{10,13}$. In addition, for behavioral experiments optogenetic stimulation or inhibition was alternated in repeated time epochs to ensure consistency in behavioral responses. For in vivo imaging experiments, odor was delivered in multiple trials for the same reason and in addition at least 50 neurons were recorded from each mouse, thus for these experiments 4 biological replicates yielded a large sample of data with consistent responses across mice and cells.

For experiments with hormone or light conditions Two-Way ANOVA's were conducted with Bonferroni Post-hoc analyses. For anatomy experiments and AUC for FSCV Unpaired Student's t-tests were conducted. For cumulative frequency distributions KolmogorovSmirov tests were conducted. For in vivo imaging a Wilcoxon paired t-test compared cell responses between odors or treatments. In all statistical measures a $\mathrm{p}$ value $<0.05$ was considered statistically significant. To calculate behavioral preference indices, calculations were used based on prior studies ${ }^{17}$ where the amount of time spent investigating the stimulant of interest (e.g. opposite-sex odor or social stimulus) and the control side (e.g. control odor, saline or same-sex social stimulus) were scored using Noldus and the Preference Index $(\Delta t / \Sigma t)$ for the stimulus was calculated as follows:

$$
\begin{gathered}
\mathrm{PI}=\left(\sum \text { Time spent investigating stimulant }-\sum \text { Time spent investigating control }\right) \\
\left(\sum \text { Time spent investigating stimulant }+\sum \text { Time spent investigating control }\right)
\end{gathered}
$$

\section{Data availability}

All custom codes have been made publically available at a GitHub repository affiliated with Stuber Lab group and this manuscript title (www.github.com/stuberlab). The data that support the findings of this study are available from the corresponding author upon reasonable request.

\section{Supplementary Material}

Refer to Web version on PubMed Central for supplementary material.

\section{Acknowledgments}


supported by ABMRF and NIAAA (K01 AA020911) and JER was supported by NIAAA (F30AA021312). This study was supported by funds from the Foundation of Hope, the Brain and Behavior Research Foundation, the Simons Foundation, the National Institute on Drug Abuse (R01 DA032750 and R01 DA038168) (GDS), the Department of Psychiatry at UNC-CH, and the National Institute on Alcohol Abuse and Alcoholism (AA022449) (EAB).

\section{References}

1. Anderson DJ, Adolphs R. A framework for studying emotions across species. Cell. 2014; 157:187200. [PubMed: 24679535]

2. Yang T, Shah NM. Molecular and neural control of sexually dimorphic social behaviors. Curr Opin Neurobiol. 2016; 38:89-95. [PubMed: 27162162]

3. Dulac C, O'Connell LA, Wu Z. Neural control of maternal and paternal behaviors. Science. 2014; 345:765-770. [PubMed: 25124430]

4. McHenry JA, Rubinow DR, Stuber GD. Maternally responsive neurons in the bed nucleus of the stria terminalis and medial preoptic area: Putative circuits for regulating anxiety and reward. Front Neuroendocrinol. 2015; 38:65-72. [PubMed: 25910426]

5. Yoest KE, Cummings JA, Becker JB. Estradiol, dopamine and motivation. Cent Nerv Syst Agents Med Chem. 2014; 14:83-89. [PubMed: 25540977]

6. Rilling JK, Young LJ. The biology of mammalian parenting and its effect on offspring social development. Science. 2014; 345:771-776. [PubMed: 25124431]

7. Petrulis A. Chemosignals and hormones in the neural control of mammalian sexual behavior. Front Neuroendocrinol. 2013; 34:255-267. [PubMed: 23911848]

8. O'Connell LA, Hofmann HA. Evolution of a vertebrate social decision-making network. Science. 2012; 336:1154-1157. [PubMed: 22654056]

9. Hull EM, Dominguez JM. Sexual behavior in male rodents. Horm Behav. 2007; 52:45-55. [PubMed: 17499249]

10. Bromberg-Martin ES, Matsumoto M, Hikosaka O. Dopamine in motivational control: rewarding, aversive, and alerting. Neuron. 2010; 68:815-834. [PubMed: 21144997]

11. Berridge KC. The debate over dopamine's role in reward: the case for incentive salience. Psychopharmacology (Berl). 2007; 191:391-431. [PubMed: 17072591]

12. Tobiansky DJ, et al. Estradiol in the Preoptic Area Regulates the Dopaminergic Response to Cocaine in the Nucleus Accumbens. Neuropsychopharmacology. 2015; doi: 10.1038/npp.2015.360

13. Tobiansky DJ, et al. The medial preoptic area modulates cocaine-induced activity in female rats. Behav Neurosci. 2013; 127:293-302. [PubMed: 23565937]

14. Wu Z, Autry AE, Bergan JF, Watabe-Uchida M, Dulac CG. Galanin neurons in the medial preoptic area govern parental behaviour. Nature. 2014; 509:325-330. [PubMed: 24828191]

15. Kempadoo KA, et al. Hypothalamic neurotensin projections promote reward by enhancing glutamate transmission in the VTA. J Neurosci. 2013; 33:7618-7626. [PubMed: 23637156]

16. Alexander MJ, et al. Estrogen induces neurotensin/neuromedin $\mathrm{N}$ messenger ribonucleic acid in a preoptic nucleus essential for the preovulatory surge of luteinizing hormone in the rat. Endocrinology. 1989; 125:2111-2117. [PubMed: 2791980]

17. Smith MJ, Wise PM. Neurotensin gene expression increases during proestrus in the rostral medial preoptic nucleus: potential for direct communication with gonadotropin-releasing hormone neurons. Endocrinology. 2001; 142:3006-3013. [PubMed: 11416022]

18. Watters JJ, Dorsa DM. Transcriptional effects of estrogen on neuronal neurotensin gene expression involve cAMP/protein kinase A-dependent signaling mechanisms. J Neurosci. 1998; 18:66726680. [PubMed: 9712639]

19. Chen TW, et al. Ultrasensitive fluorescent proteins for imaging neuronal activity. Nature. 2013; 499:295-300. [PubMed: 23868258]

20. Leinninger GM, et al. Leptin action via neurotensin neurons controls orexin, the mesolimbic dopamine system and energy balance. Cell Metab. 2011; 14:313-323. [PubMed: 21907138]

21. Asaba A, Hattori T, Mogi K, Kikusui T. Sexual attractiveness of male chemicals and vocalizations in mice. Front Neurosci. 2014; 8:231. [PubMed: 25140125] 
22. Bueno J, Pfaff DW. Single unit recording in hypothalamus and preoptic area of estrogen-treated and untreated ovariectomized female rats. Brain Res. 1976; 101:67-78. [PubMed: 1244221]

23. Yagi K. Changes in firing rates of single preoptic and hypothalamic units following an intravenous administration of estrogen in the castrated female rat. Brain Res. 1973; 53:343-352. [PubMed: 4706033]

24. Root CM, Denny CA, Hen R, Axel R. The participation of cortical amygdala in innate, odourdriven behaviour. Nature. 2014; 515:269-273. [PubMed: 25383519]

25. Hori T, Ide M, Miyake T. Ovarian estrogen secretion during the estrous cycle and under the influence of exogenous gonadotropins in rats. Endocrinol Jpn. 1968; 15:215-222. [PubMed: 5755227]

26. Caligioni CS. Assessing reproductive status/stages in mice. Curr Protoc Neurosci. 2009 Appendix 4, Appendix 4I.

27. Edwards DA. Induction of estrus in female mice: Estrogen-progesterone interactions. Hormones and Behavior. 1970; 1:299-304.

28. Stowers L, Liberles SD. State-dependent responses to sex pheromones in mouse. Curr Opin Neurobiol. 2016; 38:74-79. [PubMed: 27093585]

29. Caroom D, Bronson FH. Responsiveness of female mice to preputial attractant: effects of sexual experience and ovarian hormones. Physiol Behav. 1971; 7:659-662. [PubMed: 5164357]

30. Tan KR, et al. GABA neurons of the VTA drive conditioned place aversion. Neuron. 2012; 73:1173-1183. [PubMed: 22445344]

31. van Zessen R, Phillips JL, Budygin EA, Stuber GD. Activation of VTA GABA neurons disrupts reward consumption. Neuron. 2012; 73:1184-1194. [PubMed: 22445345]

32. Nieh EH, et al. Inhibitory Input from the Lateral Hypothalamus to the Ventral Tegmental Area Disinhibits Dopamine Neurons and Promotes Behavioral Activation. Neuron. 2016; doi: 10.1016/ j.neuron.2016.04.035

33. Stuber GD, Wise RA. Lateral hypothalamic circuits for feeding and reward. Nat Neurosci. 2016; 19:198-205. [PubMed: 26814589]

34. Jennings JH, et al. Distinct extended amygdala circuits for divergent motivational states. Nature. 2013; 496:224-228. [PubMed: 23515155]

35. Nieh EH, et al. Decoding Neural Circuits that Control Compulsive Sucrose Seeking. Cell. 2015; 160:528-541. [PubMed: 25635460]

36. Phelan MM, et al. The structure, stability and pheromone binding of the male mouse protein sex pheromone darcin. PLoS ONE. 2014; 9:e108415. [PubMed: 25279835]

37. Dhungel S, Urakawa S, Kondo Y, Sakuma Y. Olfactory preference in the male rat depends on multiple chemosensory inputs converging on the preoptic area. Horm Behav. 2011; 59:193-199. [PubMed: 21094648]

38. Sorwell KG, Wesson DW, Baum MJ. Sexually dimorphic enhancement by estradiol of male urinary odor detection thresholds in mice. Behav Neurosci. 2008; 122:788-793. [PubMed: 18729632]

39. Dey S, et al. Cyclic Regulation of Sensory Perception by a Female Hormone Alters Behavior. Cell. 2015; 161:1334-1344. [PubMed: 26046438]

40. Herbison AE, Theodosis DT. Neurotensin-lmmunoreactive Neurons in the Rat Medial Preoptic Area are Oestrogen-Receptive. J Neuroendocrinol. 1991; 3:587-589. [PubMed: 19215527]

41. Rønnekleiv OK, Kelly MJ. Diversity of ovarian steroid signaling in the hypothalamus. Front Neuroendocrinol. 2005; 26:65-84. [PubMed: 16009409]

42. Kow LM, Pfaff DW. Rapid estrogen actions on ion channels: A survey in search for mechanisms. Steroids. 2016; 111:46-53. [PubMed: 26939826]

43. Pfaff D, Waters E, Khan Q, Zhang X, Numan M. Minireview: estrogen receptor-initiated mechanisms causal to mammalian reproductive behaviors. Endocrinology. 2011; 152:1209-1217. [PubMed: 21325045]

44. Roepke TA, Malyala A, Bosch MA, Kelly MJ, Rønnekleiv OK. Estrogen regulation of genes important for K+ channel signaling in the arcuate nucleus. Endocrinology. 2007; 148:4937-4951. [PubMed: 17595223] 
45. Micevych P, Sinchak K. Temporal and concentration-dependent effects of oestradiol on neural pathways mediating sexual receptivity. J Neuroendocrinol. 2013; 25:1012-1023. [PubMed: 24028299]

46. Schmidt PJ, Rubinow DR. Sex hormones and mood in the perimenopause. Ann N Y Acad Sci. 2009; 1179:70-85. [PubMed: 19906233]

47. Schiller CE, Johnson SL, Abate AC, Rubinow DR, Schmidt PJ. Reproductive Steroid Regulation of Mood and Behavior. Compr Physiol. 2016; 6:1135-1160. [PubMed: 27347888]

48. Becker JB, Hu M. Sex differences in drug abuse. Frontiers in Neuroendocrinology. 2008; 29:3647. [PubMed: 17904621]

49. Lüscher C. The Emergence of a Circuit Model for Addiction. Annu Rev Neurosci. 2016; doi: 10.1146/annurev-neuro-070815-013920

\section{Online Methods References}

1. Leinninger GM, et al. Leptin Acts via Leptin Receptor-Expressing Lateral Hypothalamic Neurons to Modulate the Mesolimbic Dopamine System and Suppress Feeding. Cell Metabolism. 2009; 10:8998. [PubMed: 19656487]

2. Sparta DR, et al. Construction of implantable optical fibers for long-term optogenetic manipulation of neural circuits. Nat Protoc. 2012; 7:12-23.

3. Chen TW, et al. Ultrasensitive fluorescent proteins for imaging neuronal activity. Nature. 2013; 499:295-300. [PubMed: 23868258]

4. Resendez SL, et al. Visualization of cortical, subcortical and deep brain neural circuit dynamics during naturalistic mammalian behavior with head-mounted microscopes and chronically implanted lenses. Nat Protoc. 2016; 11:566-597. [PubMed: 26914316]

5. Edwards DA. Induction of estrus in female mice: Estrogen-progesterone interactions. Hormones and Behavior. 1970; 1:299-304.

6. Powers JB. Hormonal control of sexual receptivity during the estrous cycle of the rat. Physiol Behav. 1970; 5:831-835. [PubMed: 5535480]

7. Thompson ML, Edwards DA. Experiential and strain determinants of the estrogen-progesterone induction of sexual receptivity in spayed female mice. Hormones and Behavior. 1971; 2:299-305.

8. Byers SL, Wiles MV, Dunn SL, Taft RA. Mouse estrous cycle identification tool and images. PLoS ONE. 2012; 7:e35538. [PubMed: 22514749]

9. Caligioni CS. Assessing reproductive status/stages in mice. Curr Protoc Neurosci. 2009 Appendix 4, Appendix 4I.

10. Jennings JH, et al. Distinct extended amygdala circuits for divergent motivational states. Nature. 2013; 496:224-228. [PubMed: 23515155]

11. Sparta DR, et al. Construction of implantable optical fibers for long-term optogenetic manipulation of neural circuits. Nat Protoc. 2012; 7:12-23.

12. Jennings JH, Rizzi G, Stamatakis AM, Ung RL, Stuber GD. The inhibitory circuit architecture of the lateral hypothalamus orchestrates feeding. Science. 2013; 341:1517-1521. [PubMed: 24072922]

13. Jennings JH, et al. Visualizing hypothalamic network dynamics for appetitive and consummatory behaviors. Cell. 2015; 160:516-527. [PubMed: 25635459]

14. Dölen G, Darvishzadeh A, Huang KW, Malenka RC. Social reward requires coordinated activity of nucleus accumbens oxytocin and serotonin. Nature. 2013; 501:179-184. [PubMed: 24025838]

15. Phelan MM, et al. The structure, stability and pheromone binding of the male mouse protein sex pheromone darcin. PLoS ONE. 2014; 9:e108415. [PubMed: 25279835]

16. Kaur AW, et al. Murine pheromone proteins constitute a context-dependent combinatorial code governing multiple social behaviors. Cell. 2014; 157:676-688. [PubMed: 24766811]

17. Dey S, et al. Cyclic Regulation of Sensory Perception by a Female Hormone Alters Behavior. Cell. 2015; 161:1334-1344. [PubMed: 26046438]

18. Kaifosh P, Zaremba JD, Danielson NB, Losonczy A. SIMA: Python software for analysis of dynamic fluorescence imaging data. Front Neuroinform. 2014; 8:80. [PubMed: 25295002] 
19. Tsai HC, et al. Phasic firing in dopaminergic neurons is sufficient for behavioral conditioning. Science. 2009; 324:1080-1084. [PubMed: 19389999]

20. van Zessen R, Phillips JL, Budygin EA, Stuber GD. Activation of VTA GABA neurons disrupts reward consumption. Neuron. 2012; 73:1184-1194. [PubMed: 22445345]

21. Otis JM, Dashew KB, Mueller D. Neurobiological dissociation of retrieval and reconsolidation of cocaine-associated memory. J Neurosci. 2013; 33:1271-1281a. [PubMed: 23325262]

22. Pfaff D, Waters E, Khan Q, Zhang X, Numan M. Minireview: estrogen receptor-initiated mechanisms causal to mammalian reproductive behaviors. Endocrinology. 2011; 152:1209-1217. [PubMed: 21325045]

23. Kow LM, Pfaff DW. Rapid estrogen actions on ion channels: A survey in search for mechanisms. Steroids. 2016; 111:46-53. [PubMed: 26939826]

24. Woolley CS. Acute effects of estrogen on neuronal physiology. Annu Rev Pharmacol Toxicol. 2007; 47:657-680. [PubMed: 16918306]

25. Oberlander JG, Woolley CS. 17 $\beta$-Estradiol Acutely Potentiates Glutamatergic Synaptic Transmission in the Hippocampus through Distinct Mechanisms in Males and Females. J Neurosci. 2016; 36:2677-2690. [PubMed: 26937008] 
a
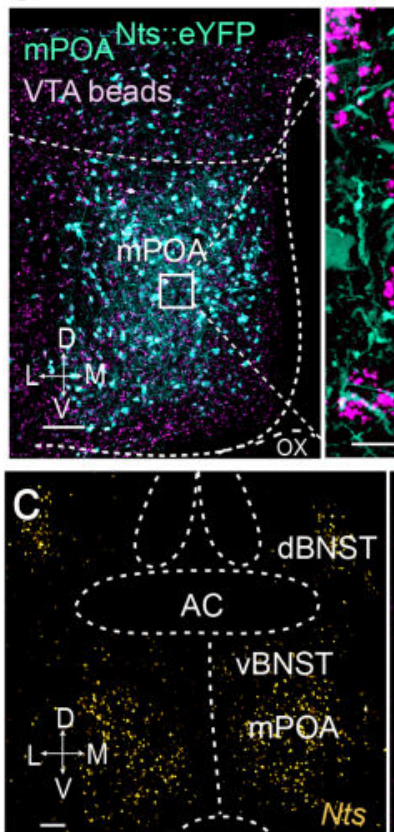
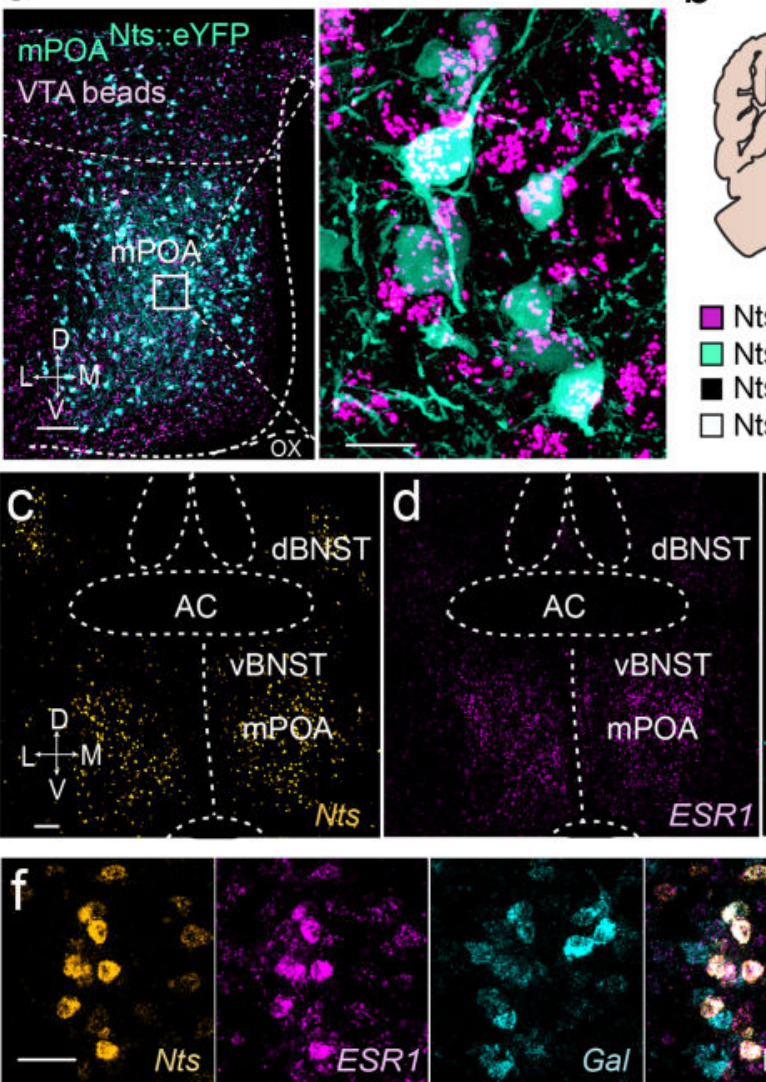

b
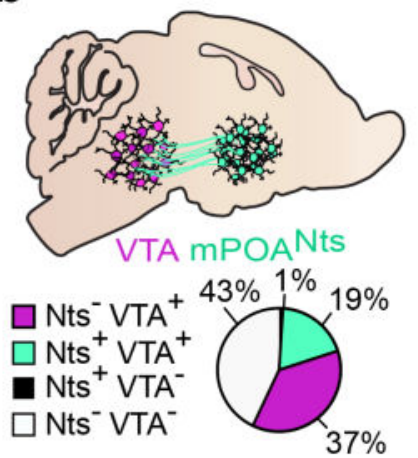

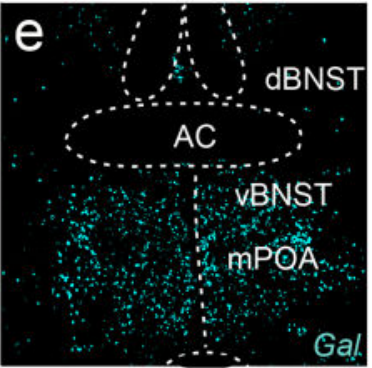

Figure 1.

Identification of a molecularly-defined population of steroid-responsive mPOA-VTA neurons. (a) Confocal images represent $\mathrm{mPOA}^{\mathrm{Nts}:: \mathrm{eYFP}}$ (teal) and Retrobead aggregates from the VTA (magenta). mPOA: medial preoptic area, VTA: ventral tegmental area; Nts: neurotensin, eYFP: enhanced yellow fluorescent protein, D: dorsal, V: ventral, M: medial, L: lateral. Left scale bar, $100 \mu \mathrm{m}$, right scale bar $20 \mu \mathrm{m}$. (b) Schematic illustrates mPOA ${ }^{\mathrm{Nts}}$ projections to the VTA and pie chart shows the percentage of mPOA neurons that contain VTA Retrobeads and/or Nts-eYFP. (c) Confocal image of Nts mRNA. BNST: bed nucleus of the stria terminalis; AC: anterior commissure, Scale bar: $100 \mu \mathrm{m}$. (d) Confocal image of ESR1 mRNA. ESR1: estrogen receptor 1/a gene. (e) Confocal image of GalmRNA. Gal: galanin gene. (f) Overlay of Nts, ESR1, and GalmRNA in the mPOA. Scale bar $60 \mu \mathrm{m}$. (g) Pie chart illustrates the percentage of ESR1 and Gal overlap within Nts positive cells. 
a

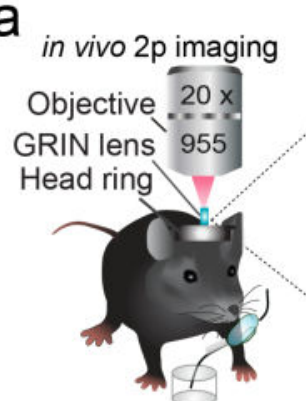

Odor delivery $\frac{\text { Pre Odor Post }}{10 s 10 s 20 s} \times 6$

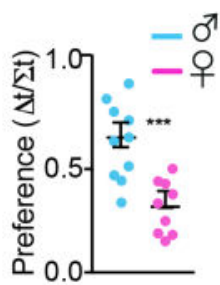

b $\mathrm{mPOA}^{\mathrm{Nts}}$ GCaMP6s

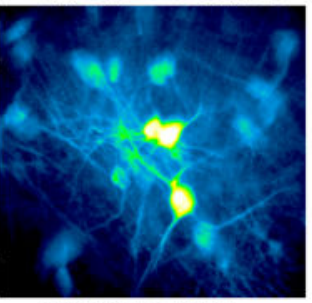

Single neuron
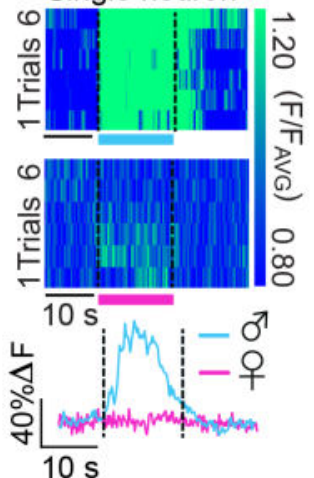

C

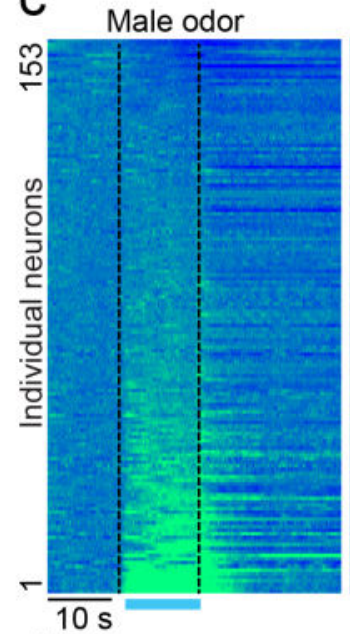

d

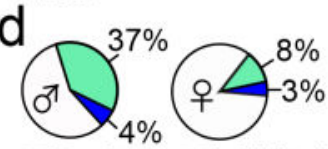

$\square$ Excited
Female odor
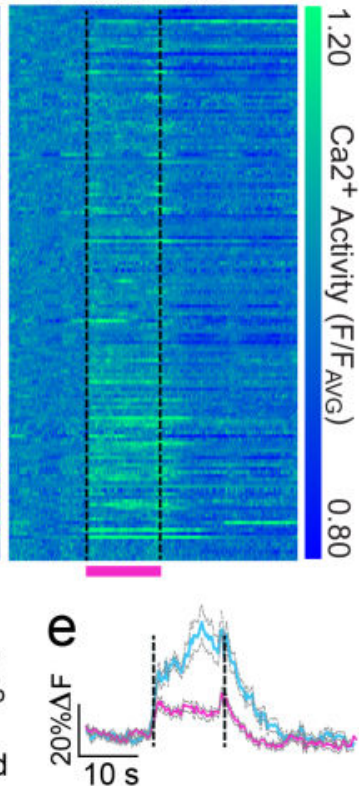

Figure 2.

mPOA $^{\text {Nts }}$ neurons dynamically encode social odor cues. (a) Top: schematic of in vivo $\mathrm{Ca}^{2+}$ imaging in mPOA ${ }^{\text {Nts::GCaMP6 }}$ cells in head-fixed mice in conjunction with delivery of vaporized mouse urine. GRIN, gradient refractive index lens. Bottom: females had a higher behavioral preference index for male urine over female urine (error bars, \pm s.e.m., paired $t$ test, $t_{17}=4.215, P=0.0006, n=9-10$ mice). (b) Top: representative $\mathrm{mPOA}^{\mathrm{Nts}:: \mathrm{GCaMP} 6}$ cells acquired from two-photon imaging (scale bars cannot be accurately provided, as two-photon recording through a GRIN lens distorts the imaging plane). Middle: each row of the heat plot

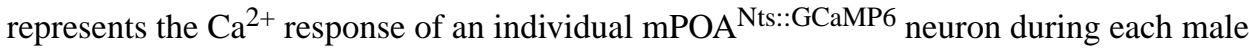
(top) or female (bottom) trial of odor delivery. Vertical axis: normalized $\mathrm{Ca}^{2+}$ fluorescence $\left(F / F_{\mathrm{AVG}}\right)$. Bottom: $\mathrm{Ca}^{2+}$ trace from the same neuron averaged across the 6 male or female odor trials. (c) Each row of the heat plot depicts the $\mathrm{Ca}^{2+}$ response of an individual

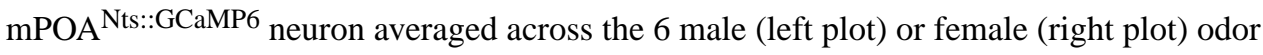
trials. Heat plots are indexed in the same order for odor type comparison and cells were sorted by male odor response ( $n=153$ cells combined across 4 mice). (d) Pie charts show the percentage of mPOA ${ }^{\text {Nts::GCaMP6 }}$ cells significantly excited or inhibited by male or female odors (Wilcoxon $t$-test, all $P<0.05, n=153$ cells combined across 4 mice). (e) $\mathrm{Ca}^{2+}$ traces averaged across male or female trials from mPOA ${ }^{\mathrm{Nts}: \mathrm{GCaMP} 6}$ cells significantly excited by male odor (error bands, \pm s.e.m.; paired $t$-test, $t_{56}=4.89, P<0.0001, n=57$ cells combined across 4 mice). 

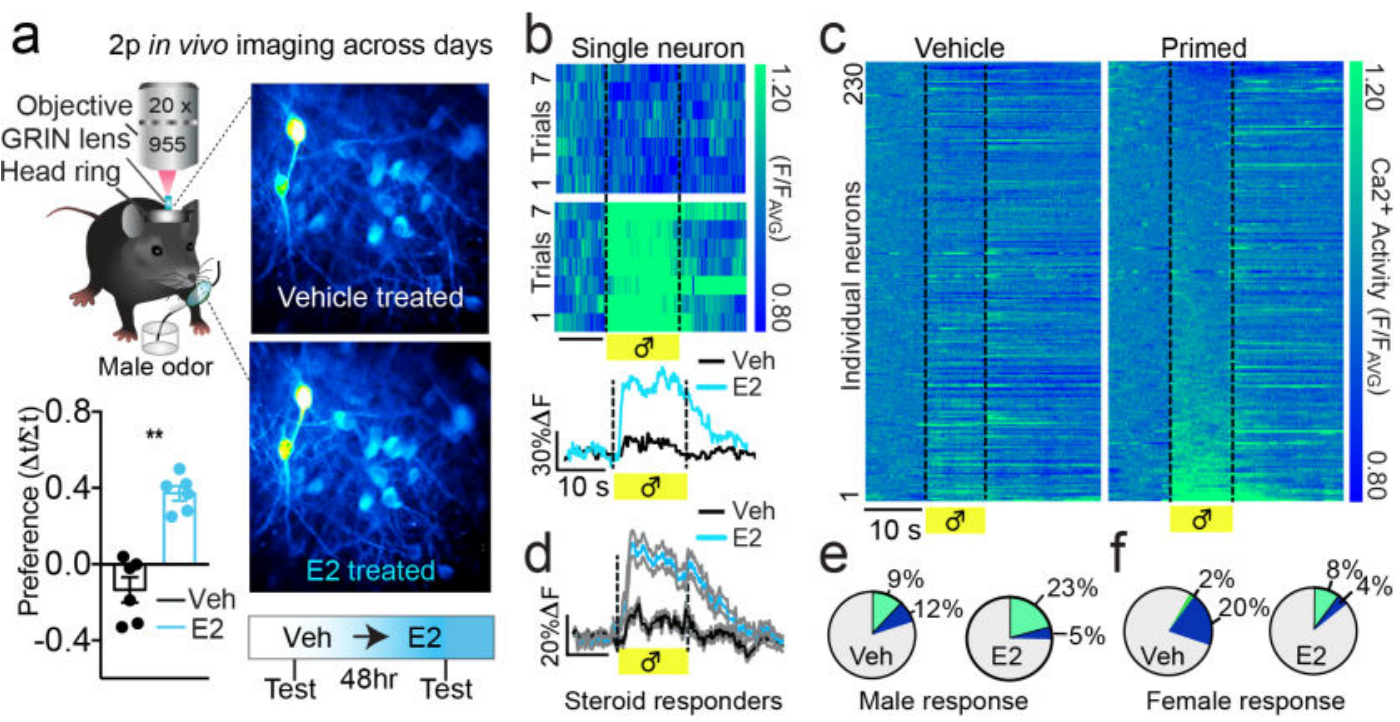

Figure 3.

mPOA $^{\text {Nts }}$ neurons encode reproductive male cues in a steroid-gated manner. (a) Top: schematic illustrating chronic $\mathrm{Ca}^{2+}$ imaging in $\mathrm{mPOA}^{\mathrm{Nts}:: G C a M P 6}$ cells on separate hormonetreated days. Bottom: ovariectomized females had a higher behavioral preference for male urine following estradiol (blue) compared to vehicle (black) (error bars, \pm s.e.m., paired $t$ test, $t_{5}=5.85, P=0.0021, n=6$ mice). (b) Top: each row of the heat plot represents the $\mathrm{Ca}^{2+}$ response during each male odor trial from an individual $\mathrm{mPOA}^{\mathrm{Nts}:: \mathrm{GCaMP} 6}$ cell imaged across treatment days. Vertical axis: normalized $\mathrm{Ca}^{2+}$ fluorescence $\left(F / F_{\mathrm{AVG}}\right)$. Scale bar, $10 \mathrm{~s}$. Bottom: $\mathrm{Ca}^{2+}$ traces from the same neuron averaged across the 7 male odor trials. Scale bar: $x, 10 \mathrm{~s} ; y, 30 \% Æ F F$. Veh, vehicle oil; E2, estradiol. (c) Each row of the heat plot depicts the $\mathrm{Ca}^{2+}$ response of an individual mPOA ${ }^{\text {Nts::GCaMP6 }}$ cell averaged across male odor trials and imaged after vehicle (left plot) or estradiol (right plot). Heat plots are indexed in the same order for comparison and cells were sorted by male odor response following estradiol replacement. Scale bar, $10 \mathrm{~s}$ ( $n=230$ cells combined across 4 mice). (d) Averaged $\mathrm{Ca}^{2+}$ traces from mPOA ${ }^{\mathrm{Nts}: \mathrm{GCaMP} 6}$ cells significantly excited by male odor after estradiol compared to their response after vehicle. Scale bar: $x, 10 \mathrm{~s} ; y, 20 \% Æ F / F$ (gray shading represents \pm s.e.m., paired $t$-test, $t_{49}=8.98, P<0.0001, n=51$ cells combined across 4 mice). (e) Pie charts represent the percent of cells significantly excited (green) or inhibited (blue) by male odor by treatment (Wilcoxon $t$-test, all $P<0.05, n=230$ cells combined across 4 mice). (f) Pie charts represent the percent of cells significantly excited (green) or inhibited (blue) by female odor by treatment (Wilcoxon $t$-test, all $P<0.05, n=230$ cells combined across 4 mice). 
a

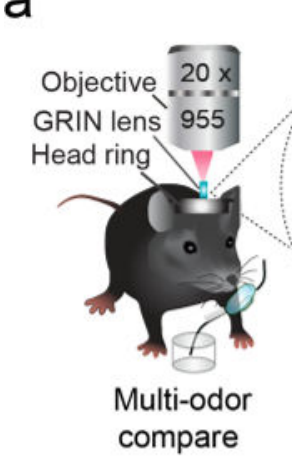

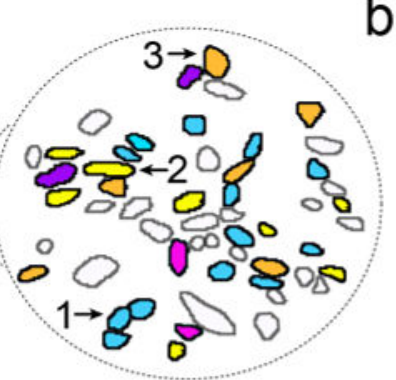

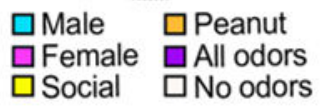

b

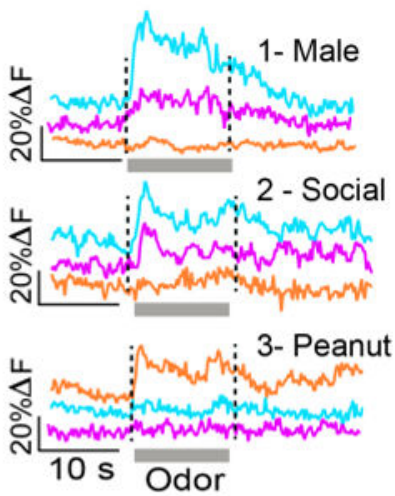

C Male odor
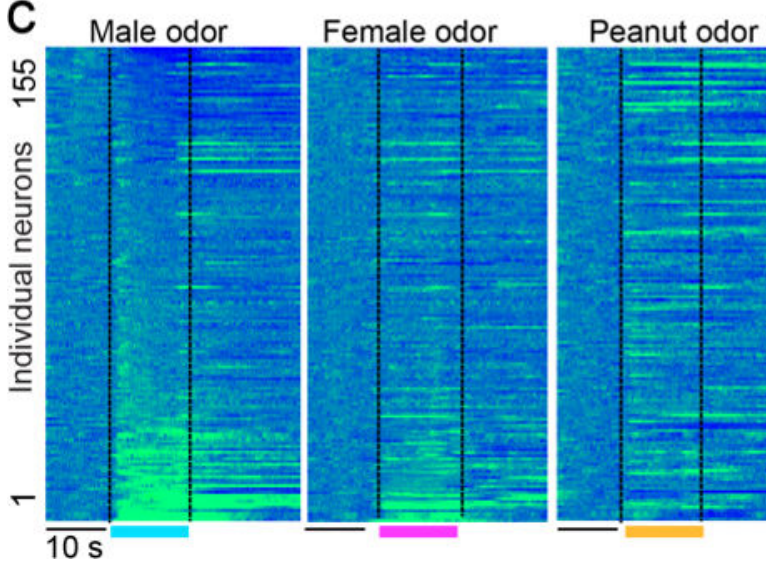

$d$

Figure 4.

$\mathrm{mPOA}^{\mathrm{Nts}}$ encoding comparison of social and nonsocial odor cues. (a) Spatial map of cell outlines in response to distinct odor cues. Mask displays binary odor response of cells excited by male odor (blue), female odor (pink), both male and female odor (yellow), nonsocial peanut oil odor (orange), all odors (purple), or none of the odors (white). (b) Example $\mathrm{Ca}^{2+}$ trace from 3 neurons indicated by arrows in the spatial map. Traces were averaged across 7 odor trials for male urine, female urine, or peanut oil. (c) Each row of the heat plot depicts the $\mathrm{Ca}^{2+}$ response of an individual mPOA ${ }^{\text {Nts::GCaMP6 }}$ neuron averaged across male (left plot), female (middle plot), or peanut (right) odor trials. Heat plots are indexed in the same order for comparison and cells were sorted by male odor response. Scale bar; $10 \mathrm{~s}(\mathrm{n}=$ 155 cells combined across 3 mice). PN: peanut oil. (d) Pie charts show the percentage of mPOA $^{\text {Nts::GCaMP6 }}$ cells significantly excited or inhibited by male, female, or peanut odors (Wilcoxon t-test, all $\mathrm{p}$ values $<0.05, \mathrm{n}=155$ cells combined across 3 mice). 

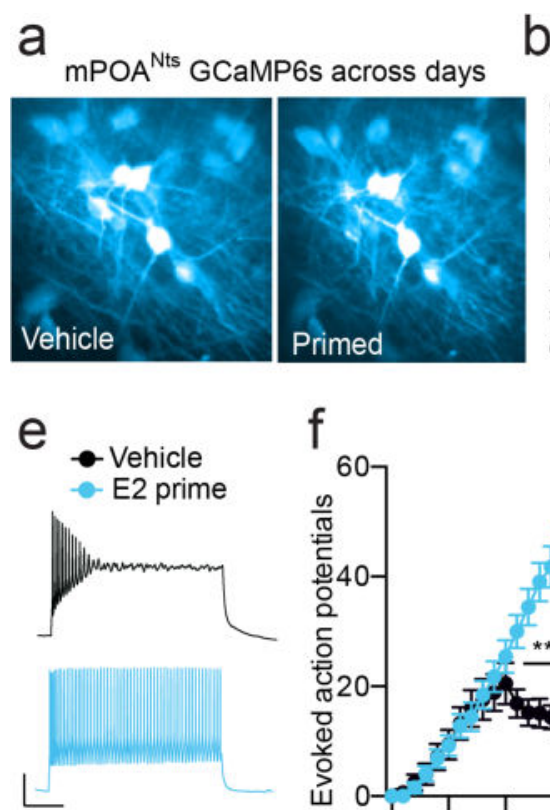
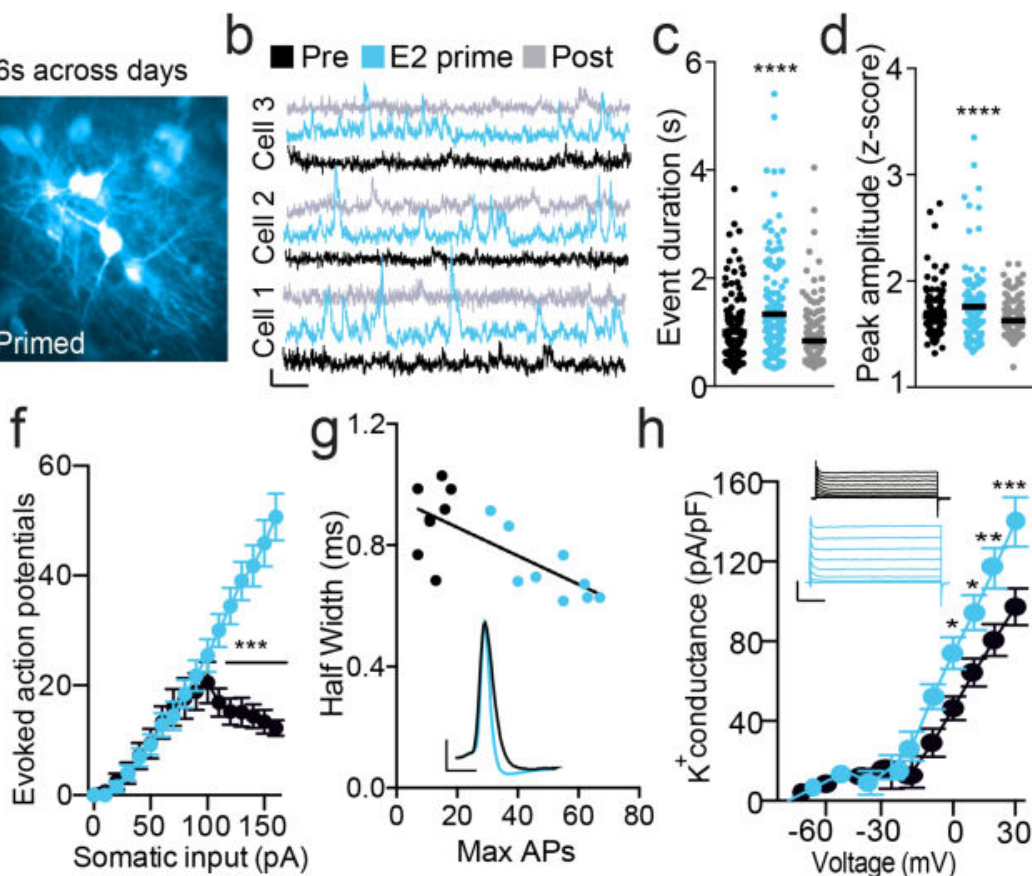

$\mathrm{h}$

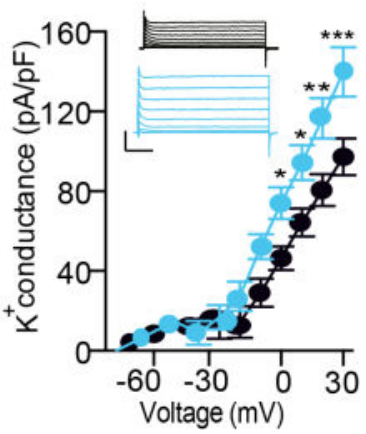

Figure 5.

Estradiol enhances neuronal excitability in $\mathrm{mPOA}^{\mathrm{Nts}}$ neurons. (a) Two-photon image of the same $\mathrm{mPOA}^{\mathrm{Nts}:: \mathrm{GCaMP} 6}$ cells imaged after vehicle or estradiol priming. (b) Example $\mathrm{Ca}^{2+}$ traces showing normalized fluorescence $F / F_{0}$ of GCaMP6s $\mathrm{Ca}^{2+}$ dynamics from the same $\mathrm{mPOA}^{\mathrm{Nts}: \mathrm{GCaMP} 6}$ on different treatment days. Pre, vehicle 1 week before estradiol replacement; E2 prime, $5 \mathrm{~h}$ after estradiol; post, vehicle 1 week after estradiol (b-d). Scale bar: $x, 20 \mathrm{~s} ; y, 20 \% \Subset F F$. (c) $\mathrm{mPOA}^{\mathrm{Nts}:: G C a M P 6}$ cells displayed $\mathrm{Ca}^{2+}$ events longer in duration after estradiol treatment (bars are means; data points, individual cells; repeatedmeasures (RM) ANOVA, $F_{2,252}=35.46, P<0.0001, n=143$ cells combined across 4 mice). (d) $\mathrm{mPOA}^{\mathrm{Nts}:: \mathrm{GCaMP} 6}$ cells displayed $\mathrm{Ca}^{2+}$ events higher in amplitude after estradiol treatment (error bars, \pm s.e.m., RM one-way ANOVA, $F_{2,252}=17.32, P<0.0001, n=143$ cells combined across 4 mice). (e) Example traces of current-clamp recordings in mPOA $^{\text {Nts::eYFP }}$ cells from ovariectomized mice by treatment. Scale bars: $x, 200 \mathrm{~ms} ; y, 25$ $\mathrm{mV}$. In e-g, black represents vehicle; blue, estradiol. (f) $\mathrm{mPOA}^{\mathrm{Nts}:: \mathrm{eYFP}}$ cells from estradioltreated mice have more evoked action potentials with increasing current (error bars, \pm s.e.m.; two-way ANOVA, interaction $F_{16,240}=32.40, P<0.0001$, vehicle: $n=8$ cells, E2: $n=9$ cells; 3 mice per group). (g) Inset: representative action potential from recordings in a $\mathrm{m}^{\text {POANts::eYFP }}$ cell by treatment. Scale bars: $x, 2 \mathrm{~ms}, y, 25 \mathrm{mV}$. Correlation plot: $\mathrm{m}^{\text {POANts::eYFP }}$ cells from estradiol-treated mice were correlated with a decrease in spike half-width (error bars, \pm s.e.m., Pearson $R^{2}=0.53, P=0.0010$, vehicle: $n=8$ cells, E2: $n=9$ cells, 3 mice per group). (h) Inset: Example traces of A-type isolated potassium channel recordings in mPOA $^{\text {Nts::eYFP }}$ cells by treatment. Scale bars: $x, 25 \mathrm{~ms} ; y, 2.5 \mathrm{nA}$. Graph: Atype potassium current conductance is greater in $\mathrm{mPOA}^{\mathrm{Nts}:: \mathrm{eYFP}}$ cells treated with estradiol (error bars, \pm s.e.m.; two-way ANOVA, interaction $F_{11,308}=5.88, P<0.0001$, vehicle: $n=$ 13 cells, E2: $n=17$ cells, vehicle: 2 mice; E2: 3 mice). 
a

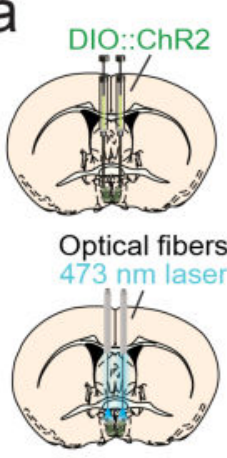

f

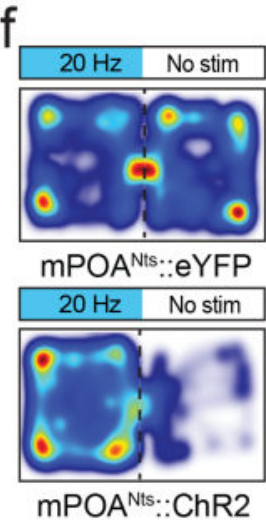

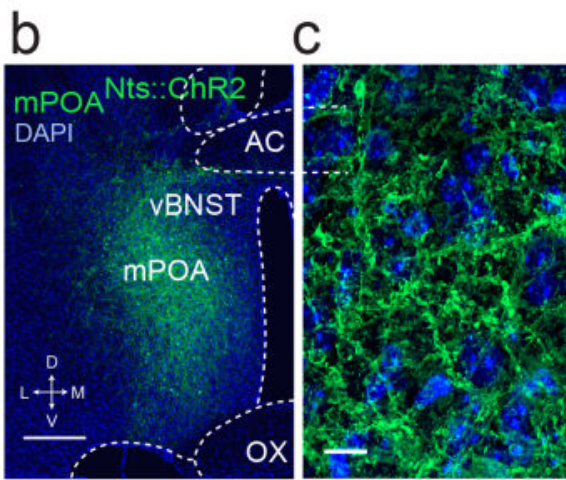
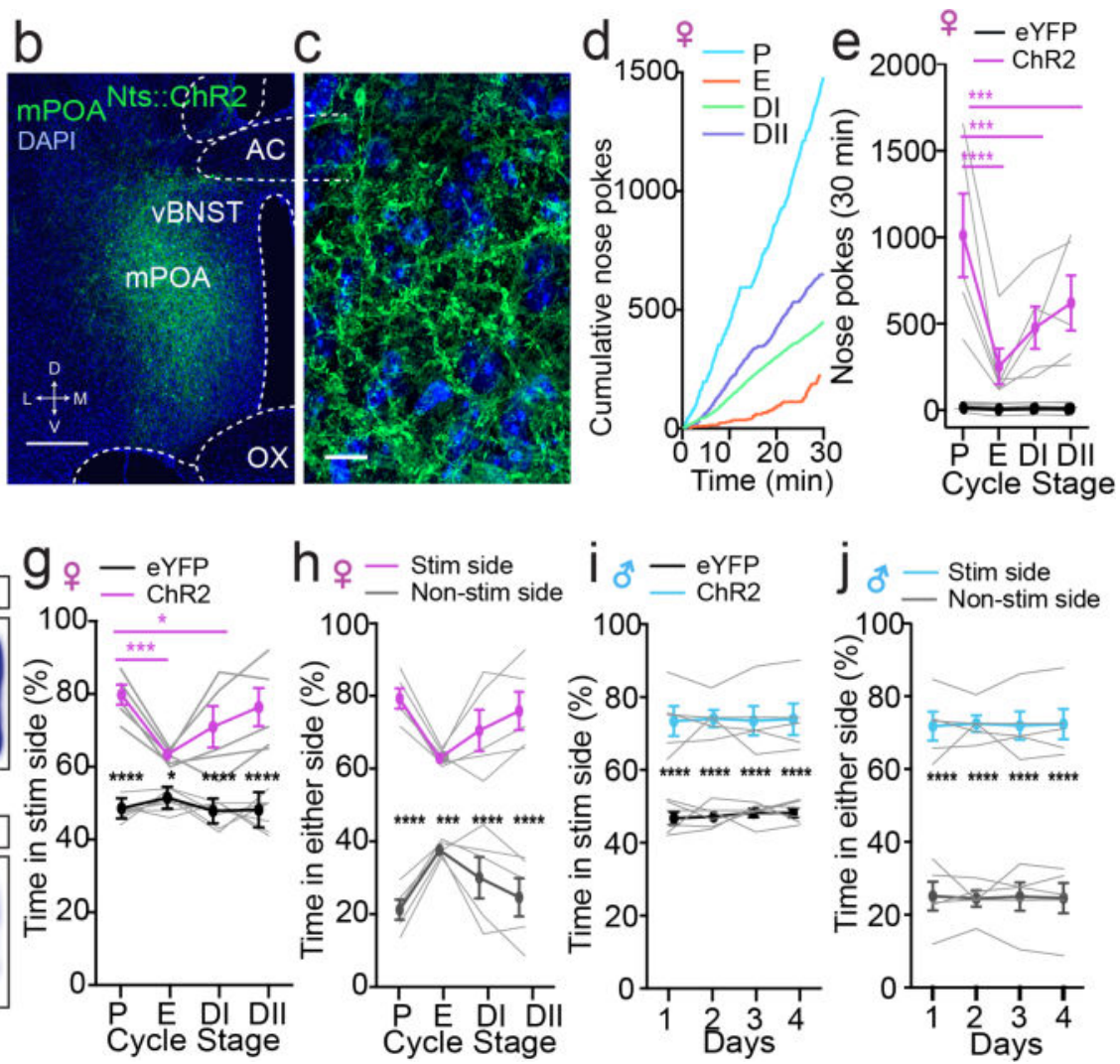

Figure 6.

Stimulation of $\mathrm{mPOA}^{\mathrm{Nts}}$ neurons is reinforcing in both sexes. (a) Schematic depicting viral and optogenetic approach for stimulation of $\mathrm{mPOA}^{\mathrm{Nts}}$ neurons. (b) Confocal image of mPOA $^{\text {Nts }}$ ChR2-eYFP expression (green) and DAPI (blue). vBNST: ventral bed nucleus of the stria terminalis, AC: anterior commissure, OX: optic chiasm, D: dorsal, V: ventral, M: medial, L: lateral; scale bar, 200 ìm. (c) Confocal image of mPOA ${ }^{\text {Nts }}$ ChR2-eYFP (green) and DAPI (blue). Scale bar, 20 ìm. (d) Cumulative nose poke performed for self-stimulation in each stage of the estrous cycle from a representative $\mathrm{mPOA}^{\mathrm{Nts}:: \mathrm{ChR} 2}$ female mouse. P: proestrus, E: estrus, DI: metestrus, DII: diestrus. (e) $\mathrm{mPOA}^{\mathrm{Nts}:: \mathrm{ChR} 2}$ female mice readily nosepoke in the active port to obtain photostimulation and $\mathrm{mPOA}^{\text {Nts::eYFP }}$ controls do not.

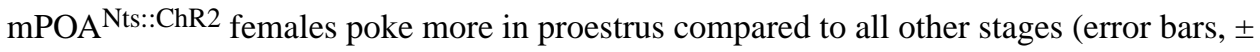
s.e.m., two-way ANOVA, interaction $F_{3,27}=12.70, P<0.0001$, ChR $2 n=5$, eYFP $=6$ mice). Individual data points are shown as gray lines. (f) Color heat maps illustrating the spatial location in the real-time place preference for a representative $\mathrm{mPOA}^{\mathrm{Nts}: \mathrm{ChR} 2}$ female and $\mathrm{mPOA}^{\mathrm{Nts}:: \mathrm{eYFP}}$ control mouse in proestrus. (g) $\mathrm{mPOA}^{\mathrm{Nts}:: \mathrm{ChR} 2}$ female mice spent significantly more time in the photostimulation side of the chamber in all stages compared to $\mathrm{mPOA}^{\mathrm{Nts}:: \mathrm{eYFP}}$ females and had a higher preference in proestrus compared to estrus and metestrus (error bars, \pm s.e.m., two-way ANOVA, interaction $F_{3,30}=9.44, P=0.0002$, ChR2 $n=5$, eYFP $=7$ mice). (h) $\mathrm{mPOA}^{\mathrm{Nts}:: \mathrm{ChR} 2}$ female mice spent significantly more time in the photostimulation side of the chamber compared to the non-photostimulation side in all stages of the cycle (error bars, \pm s.e.m., two-way ANOVA, interaction $F_{3,24}=15.2, P<$ $0.0001, \mathrm{ChR} 2 n=5, \mathrm{eYFP}=5$ mice). (i) $\mathrm{mPOA}^{\mathrm{Nts}:: \mathrm{ChR} 2}$ males spent significantly more time 
in the stimulation side of the chamber compared to $\mathrm{mPOA}^{\mathrm{Nts}:: \mathrm{YYF}}$ controls, with no effect of day (error bars, \pm s.e.m., two-way ANOVA, group effect, $F_{1,9}=63.1, P<0.0001, n=5-6$ mice per group). (j) $\mathrm{mPOA}^{\mathrm{Nts}:: \mathrm{ChR} 2}$ male mice spent significantly more time in the photostimulation side of the chamber compare to the non-photostimulation on all $4 \mathrm{~d}$ (error bars, \pm s.e.m., two-way ANOVA, group effect $F_{1,8}=92.75, P<0.0001, n=5$ mice per group). 
a
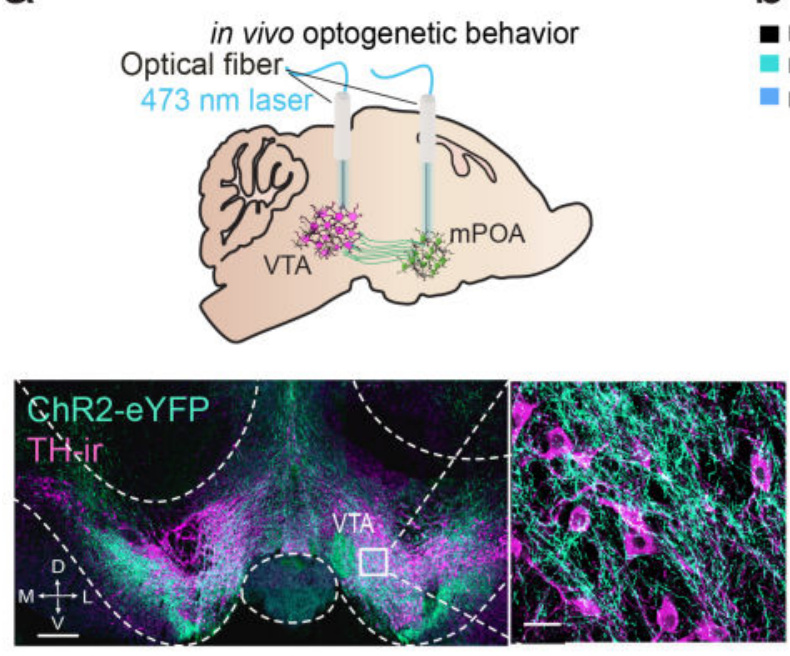

C

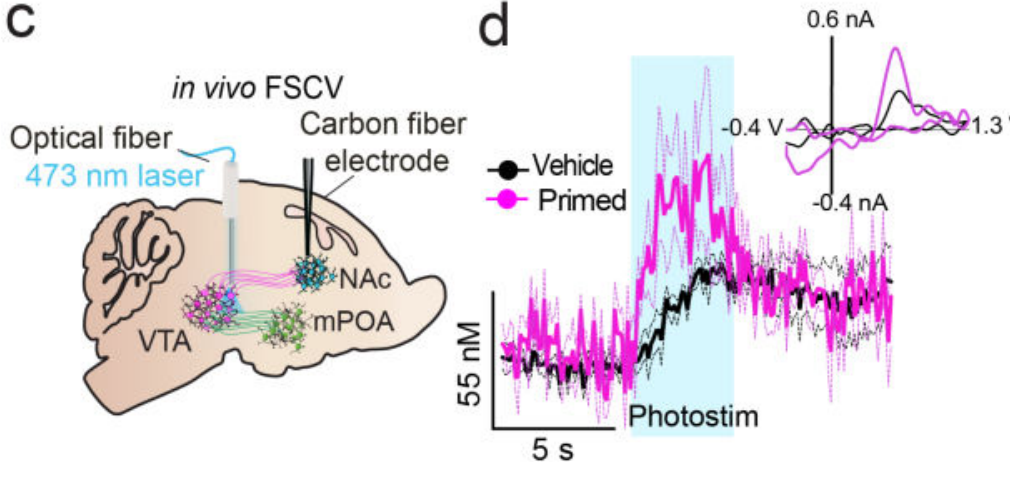

b mPOA eYFP
mPOA ChR2 Veh $=\mathrm{mPOA}$ mPOA-VTA eYFP
mPOA ChR2

Pre prime Post prime

Figure 7.

Stimulation of mPOA-VTA ${ }^{\mathrm{Nts}}$ neurons is reinforcing and evokes striatal dopamine release. (a) Top: optogenetic stimulation targeted at $\mathrm{mPOA}^{\mathrm{Nts}:: \mathrm{ChR} 2}$ neurons or mPOA-VTA ${ }^{\mathrm{Nts}: \text { :ChR2 }}$ projecting fibers. Bottom: confocal image of mPOA-VTA ${ }^{\mathrm{Nts}:: \mathrm{ChR} 2}$ projecting fibers (green) and TH expression (magenta) in the VTA. TH: tyrosine hydroxylase, D: dorsal, V: ventral, M: medial, L: lateral. Left scale bar, 200 ìm. Right scale bar, 20 ìm. (b) $\mathrm{mPOA}^{:: \mathrm{ChR} 2}$ and mPOA-VTANts::ChR2 mice spent more time on the photostimulation side of the chamber, and this was amplified following estradiol priming compared with that in vehicle controls (error bars, \pm s.e.m.; two-way ANOVA, interaction $F_{4,24}=7.04, P=0.0007, n=5$ or 6 mice per group). (c) Schematic depicting optogenetic targeting of mPOA-VTA ${ }^{\mathrm{Nts}:: \mathrm{ChR} 2}$ projecting fibers in conjunction with fast-scan cyclic voltammetry (FSCV) to detect dopamine release in the nucleus accumbens (NAc) of the ventral striatum. (d) Photostimulation mPOAVTA $^{\text {Nts::ChR2 }}$ projecting fibers increased dopamine concentrations in the ventral striatum, and concentrations were higher in estradiol-treated mice (error limits, \pm s.e.m., two-way ANOVA, interaction $F_{149,1490}=1.42 P=0.0012, n=6$ mice per group). Blue bar indicates optical stimulation $(3 \mathrm{~s}, 20 \mathrm{~Hz})$. Inset: average background-subtracted cyclic voltammograms demonstrating characteristic oxidation and reduction peak potentials that identify dopamine. (e) Estradiol treatment resulted in a higher area under the curve (increased dopamine concentrations) during photostimulation of mPOA-VTA NTS:ChR2-eYFP fibers. (error bars, \pm s.e.m.; unpaired $t$-test, $t_{5.971}=3.328, P=0.016, n=6$ mice per group). 

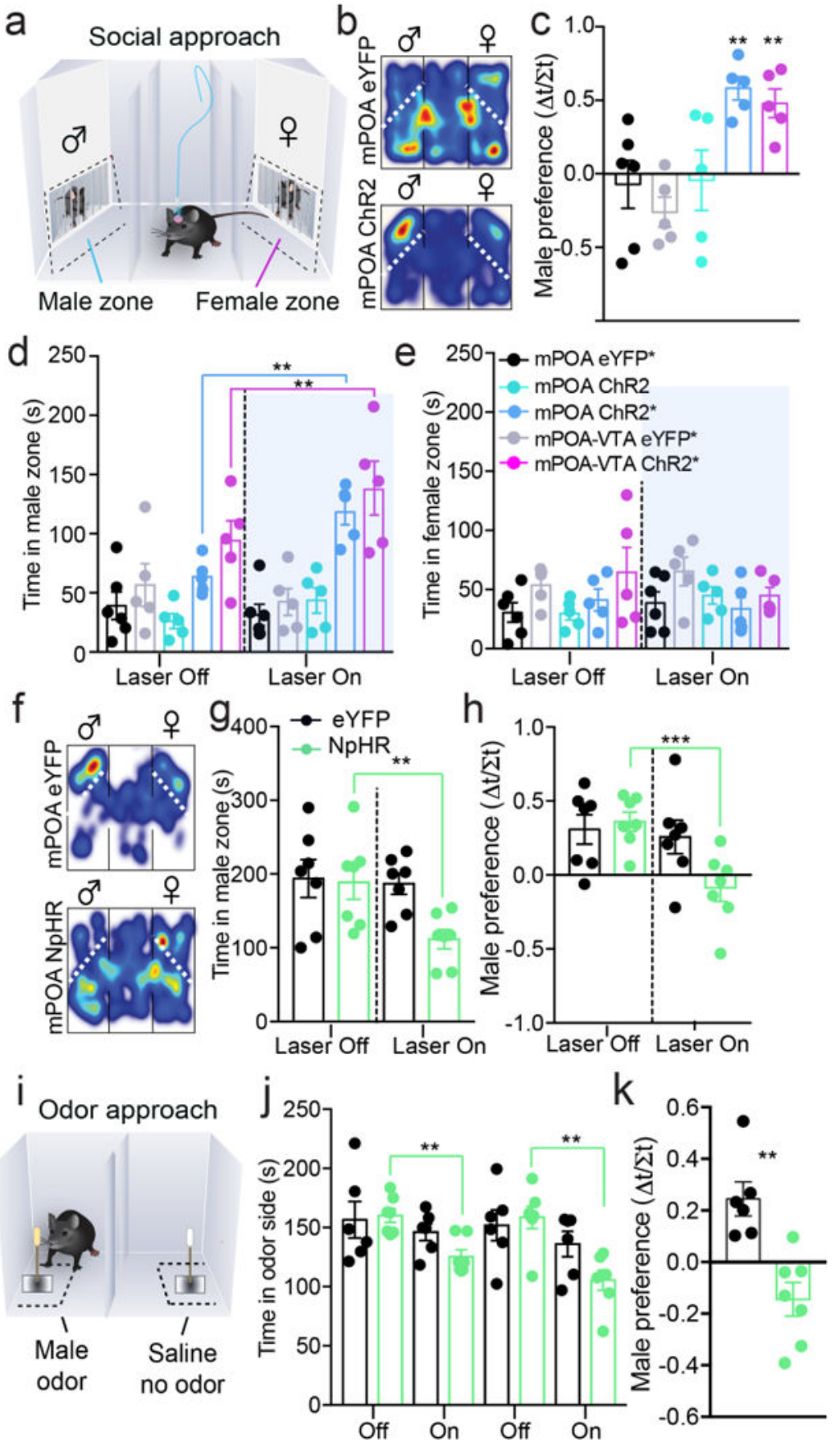

Figure 8.

Optogenetic modulation of $\mathrm{mPOA}^{\mathrm{Nts}}$ neurons regulates social attraction. (a) Schematic illustrating the social preference test for an adult male or female conspecific, tested during alternating periods of light delivery. (b) Representative color heat maps displaying the spatial location of a steroid-primed $\mathrm{mPOA}^{\mathrm{Nts}:: \mathrm{ChR} 2}$ female and steroid-primed mPOA $^{\text {Nts::eYFP }}$ control mouse in the social preference test. (c) Photoactivation enhanced male preference in $\mathrm{mPOA}: \mathrm{ChR} 2$ and $\mathrm{mPOA}-\mathrm{VTA}{ }^{\mathrm{Nts}:: \mathrm{ChR} 2}$ mice previously primed with steroids (error bars, \pm s.e.m.; one-way ANOVA, $F_{4,21}=6.82, P=0.0011, n=5$ or 6 mice per 
group). Colors and key legends are shown in $\mathbf{e}$ for $\mathbf{c}-\mathbf{e}$. Asterisk denotes mice that received prior but not recent estradiol and progesterone priming. (d) Photoactivation increased the amount of time spent in the male zone in $\mathrm{mPOA}: \mathrm{ChR} 2$ and $\mathrm{mPOA}-\mathrm{VTA}{ }^{\mathrm{Nts}:: \mathrm{ChR} 2}$ mice previously primed with steroids (error bars, \pm s.e.m.; two-way ANOVA, interaction $F_{4,21}=$ 6.35, $P=0.0016, n=5$ or 6 mice per group). (e) Photoactivation did not increase the amount of time spent in the female zone (error bars, \pm s.e.m., two-way ANOVA, interaction $F_{4,21}=$ 1.33, $P=0.29$, eYFP $n=6$, ChR2 $n=5$ ). (f) Representative color heat maps displaying the spatial location of a steroid-primed $\mathrm{mPOA}^{\mathrm{Nts}:: \mathrm{NpHR}}$ female and steroid-primed $\mathrm{mPOA}^{\mathrm{Nts}:: \mathrm{eYFP}}$ control mouse in the social preference test. (g) Steroid-primed mPOA $^{\text {Nts::NpHR }}$ females had a lower male preference during light delivery, compared to steroid-primed $\mathrm{mPOA}^{\mathrm{Nts}:: \mathrm{eYFP}}$ controls (error bars, \pm s.e.m.; two-way ANOVA, interaction $F_{1,12}=7.15, P=0.02, n=7$ mice per group). (h) Steroid-primed $\mathrm{mPOA}^{\mathrm{Nts}:: \mathrm{NpHR}}$ females spent less time in the male interaction zone during light delivery, compared to steroidprimed $\mathrm{mPOA}^{\mathrm{Nts}:: \mathrm{eYFP}}$ controls (error bars, \pm s.e.m., two-way ANOVA, interaction $F_{1,12}=$ 9.8, $P=0.009, n=7$ per mice group). (i) Illustration of a behavioral odor preference assay comparing the animal's time in the zone containing male urine or saline. (j) Steroid-primed $\mathrm{mPOA}^{\mathrm{Nts}:: \mathrm{NpHR}}$ females spent less time in the male odor zone during light delivery, compared to steroid-primed mPOA ${ }^{\text {Nts::eYFP }}$ controls (error bars, \pm s.e.m., two-way ANOVA, laser effect $F_{3,33}=6.05, P=0.0021, n=7$ mice per group). (k) Photoinhibition decreased the preference index for male odor in $\mathrm{mPOA}^{\mathrm{Nts}:: \mathrm{NpHR}}$ females (error bars, \pm s.e.m., unpaired $t$-test, $t_{11}=8.30, P<0.0001, n=6-7$ mice per group). $* P<0.05 ; * * P<0.01 ; * * * P<0.001$. 